\title{
Revisiting the taxonomy of the Rattini tribe: a phylogeny-based delimitation of species boundaries
}

\author{
Marie Pagès*1, Yannick Chaval'1, Vincent Herbreteau2,3, Surachit Waengsothorn4, Jean-François Cosson', Jean-
}

Pierre Hugot 5 , Serge Morand ${ }^{6,7}$ and Johan Michaux ${ }^{1,8}$

\begin{abstract}
Background: Rodents are recognized as hosts for at least 60 zoonotic diseases and may represent a serious threat for human health. In the context of global environmental changes and increasing mobility of humans and animals, contacts between pathogens and potential animal hosts and vectors are modified, amplifying the risk of disease emergence. An accurate identification of each rodent at a specific level is needed in order to understand their implications in the transmission of diseases. Among the Muridae, the Rattini tribe encompasses 167 species inhabiting South East Asia, a hotspot of both biodiversity and emerging and re-emerging diseases. The region faces growing economical development that affects habitats, biodiversity and health. Rat species have been demonstrated as significant hosts of pathogens but are still difficult to recognize at a specific level using morphological criteria. DNAbarcoding methods appear as accurate tools for rat species identification but their use is hampered by the need of reliable identification of reference specimens. In this study, we explore and highlight the limits of the current taxonomy of the Rattini tribe.
\end{abstract}

Results: We used the DNA sequence information itself as the primary information source to establish group membership and estimate putative species boundaries. We sequenced two mitochondrial and one nuclear genes from 122 rat samples to perform phylogenetic reconstructions. The method of Pons and colleagues (2006) that determines, with no prior expectations, the locations of ancestral nodes defining putative species was then applied to our dataset. To give an appropriate name to each cluster recognized as a putative species, we reviewed information from the literature and obtained sequences from a museum holotype specimen following the ancient DNA criteria.

Conclusions: Using a recently developed methodology, this study succeeds in refining the taxonomy of one of the most difficult groups of mammals. Most of the species expected within the area were retrieved but new putative species limits were also indicated, in particular within Berylmys and Rattus genera, where future taxonomic studies should be directed. Our study lays the foundations to better investigate rodent-born diseases in South East Asia and illustrates the relevance of evolutionary studies for health and medical sciences.

\section{Background}

Among mammals, rodents are recognized as major hosts and vectors of parasites and pathogens, some of them causing important zoonoses and representing a serious threat for human health [1-5]. Most epidemiological studies have focused on the most common rodents with emphasis on commensal species such as the laboratory

* Correspondence: marie.pages@supagro.inra.fr

1 INRA, UMR CBGP (INRA/IRD/Cirad/Montpellier SupAgro), Campus International de Baillarguet, CS 30016, 34988 Montferrier-sur-Lez cedex, France Full list of author information is available at the end of the article rat, Rattus norvegicus. A common assumption is that the rodent species responsible for disease transmission are those living close to humans, but since wild species distant from human settlements have been proven to play a key role in maintaining, spreading and transmitting pathogens and parasites (e.g. [4]), this point of view is being questionned. Specific diversity within the host community has also been shown to play an important function in the maintenance of a disease and in the probability of its transmission to humans [6,7]. Consequently, 
researchers are now focusing not on a single particular host species but on the whole host community and are endeavouring to understand the role of each rodent species in the context of the entire host-pathogen community.

Today this knowledge is more urgent than ever since biodiversity in many areas is being altered rapidly by the ongoing global change. Because of anthropogenic disturbances, the host-pathogen interactions are being dramatically modified leading to new and unexpected disease risks and the emergence and/or re-emergence of infectious diseases [6-10]. To be able to predict and to anticipate some of these risks, one should be able in the case of rodent host communities, to identify first and foremost each rodent at a specific level, a real challenge when considering that rodents represent $40 \%$ of mammalian species [11] including many cryptic species, and that new genera and species are yearly described (e.g. Laonastes aenigmamus, [12]; Saxatilomys paulinae, [13]; Mayermys germani, [14]; Tonkinomys daovantieni, [15]).

Among Muridae rodents, the Rattini tribe encompasses 35 genera corresponding to 167 rat species [16] following the tribal arrangement of the Murinae proposed by Lecompte et al. [17]. Nearly all representatives of this tribe inhabit South East Asia, a major hotspot of biodiversity [18] faced with a runaway economic growth damaging habitats, biodiversity and health but also a hotspot of emerging and re-emerging diseases $[19,20]$. If the partition of the tribe among five divisions (i.e. Crunomys, Dacnomys, Maxomys, Micromys and Rattus divisions) $[16,17]$ is widely accepted, its taxonomy remains however largely untested phylogenetically and its delimitations are not yet secured. Chiropodomys, Vandeleuria, Hapalomys, Haeromys and Vernaya genera were included in the Micromys division by Musser and Carleton [16]. As the Eurasian harvest mouse, Micromys was proven to belong to the Rattini tribe $([17,21])$, the whole Micromys division should belong to the Rattini tribe if Musser and Carleton's assumption is right. However, some of these genera (i.e. Chiropodomys and Vandeleuria) were recently shown to be unaffiliated to Micromys according to molecular evidences [21], while putative representatives of the Rattini tribe (i.e. Tonkinomys daovantieni, Saxatilomys paulinae, Srilankamys sp., Hapalomys sp., Haeromys sp., Vernaya sp.) have not been investigated using molecular data and are currently considered as Murinae incertae sedis [17]. Numerous rat species have been demonstrated or postulated as major hosts of pathogens (e.g. Hantaviruses described from bandicoot rat, Bandicota indica in Thailand, [22,23]; Bandicota indica, B. savilei, Berylmys berdmorei, Niviventer sp., and Rattus sp. serologically tested positive for Rickettsia tsutsugamushi, the agent responsible for scrub typhus [24]; etc.). Although easily identified at a generic level by an expert, Asian rats are often difficult to discriminate at a specific level using morphological or cytological criteria. The wide range of intra-specific morphological variation makes morphological criteria unsuitable for accurate rat species identification and has led to an over-description of species and to a confusing taxonomy, hampered by an overabundance of synonyms. It is particularly true concerning the Rattus genus (e.g. 41 synonyms for $R$. norvegicus, 83 for $R$. rattus, etc. [16] and see also [25]) that consists of a heterogeneous accumulation of species and of several monophyletic clusters that may or may not prove to be grouped in a single genus [16]. This polyphyletic pattern is highlighted by the six species groups proposed by Musser and Carleton [16] (i.e. the Rattus rattus, Rattus exulans, Rattus norvegicus, Rattus fuscipes, Rattus leucopus and Rattus xanthurus species groups) and a seventh assemblage containing unaffiliated species (i.e. the Rattus species group unresolved) for which phylogenetic affinities are uncertain; some representatives will eventually be removed from the genus. Even karyotypic criteria, which previously claimed to be species diagnostic tools, were recently revealed to be unsuitable to discriminate between Asian rat species [26]. DNA-based methods, however, appear to be promising tools for easy and accurate rat species-specific identifications [26].

Robins et al. [25] were the first to attempt to identify Rattus species using mitochondrial DNA sequences mostly obtained from museum tissue samples. Nevertheless, their conclusions based on DNA-barcoding and tree based methods were limited because these methods need reliably identified specimens as reference. Specimens and tissues offered by museums to scientists are collected by many different people and it seems likely, given the extent of some misidentifications, that rat species identification is not an easy task even for mammal specialists. Moreover, the taxonomy of the tribe Rattini is complex and changing and often different to that in use when samples were first described and listed in museums [25].

Level of variation in cytochrome $b$ sequences was also proposed as a reference point in making decisions concerning species-level distinctions [27]. Based on the analysis of 4 genera of rodents, Bradley and Baker [27] suggested that genetic distance values lesser than $2 \%$ were indicative of intraspecific variation and values higher than $11 \%$ of species recognition. But how to conclude between 2 and $11 \%$ ? The DNA-based species delimitation approach proposed by Pons et al. [28] relies on DNA sequence information itself as the primary information source for establishing group membership and defining putative species and does not require defining entities as priors. This method was shown to be useful for identifying meaningful entities among groups whose current taxonomy is incomplete (e.g. tiger beetles of the genus Rivacindela, [28]) or uncertain (e.g. aphids of the 
genus Brachycaudus) and has already been successfully applied when species are difficult to conceptualize (e.g. bacteria [29] or for asexual animals, [30,31]). Using a likelihood framework, this new procedure detects the point of transition in the rate of lineage branching of a tree from interspecific long branches to intraspecific short burgeoning branching and identifies clusters of specimens corresponding to putative species.

In our study, we used molecular data to test the limits of the current taxonomy of the Rattini tribe. We aimed at identifying where species boundaries are unclear and where further investigations need to be carried out to provide a more rigorous systematic framework for epidemiological surveys. As molecular data are useful to detect and distinguish morphologically similar species, this study investigated the existence of putative cryptic species among the Rattini tribe (i.e. two or more species that are classified as a single nominal species because they are at least superficially morphologically indistinguishable [32]). To these aims, we first sequenced two mitochondrial and one nuclear genes from rat specimens coming from Southeast Asia (Thailand, Cambodia and Lao People's Democratic Republic) to perform phylogenetic reconstructions. Then, as morphological characters are often misleading, we applied the method developed by Pons et al. [28] that determines, with no prior expectations, the locations of ancestral nodes to define putative species. Finally, we endeavoured to give a name to each cluster recognized as a putative species using information from the literature and also sequences obtained from a museum holotype specimen following all the ancient DNA guidelines.

\section{Methods}

\section{Sampling}

116 specimens of Rattini were selected among the 3,000 trapped by our team in the fields mostly in Thailand and punctually in Cambodia and in Lao PDR. Specimens selected were chosen in order to maximise the number of species and geographic locations analysed. Field specimen identifications and locality information are listed in Table 1 and indicated in Figure 1. Field identifications were made based on morphological criteria according to [11,33-35]. Based on morphological and cytological evidences, no specimen was identified by us as a representative of the cosmopolitan Rattus rattus species. Considering their preponderant place in epidemiological surveys, 4 worldwide black rat specimens (identified in [36]) were added to the sample set. To provide an appropriate outgroup, we included specimens of the Eurasian harvest mouse, Micromys belonging to the Rattini tribe and previously recognized as the sister lineage to the Rattus group sensu lato of Verneau et al., [37,38,17,21]. In total, our taxa sampling consisted of 122 rats.
For nomenclatural prospects, a small piece of skin from the holotype specimen of Leopoldamys neilli was also analysed in this study. The type specimen is the male $n^{\circ} 54-4330$ from the Centre for Thai National Reference collections, collected by W.A. Neill in 1973 at Wat Tham Prapothisat, in the Saraburi Province (Kaengkhoi District, Thailand, $14^{\circ} 35^{\prime} \mathrm{N} \mathrm{X} 101^{\circ} 8^{\prime} \mathrm{E}$ ) (see [33] for further details).

\section{Sequence acquisition}

Three genes proven valuable for rodent systematics were considered for the phylogenetic analyses [39,40,25,17]. We targeted two mitochondrial markers, the cytochrome $b$ (cytb) and the cytochrome c oxydase I (COI) genes and the first exon of the nuclear gene encoding the interphotoreceptor retinoid binding protein (IRBP).

To avoid contamination, pre-amplification procedures and post-amplification analyses were performed in independent rooms in the laboratory. DNA was extracted from tissue with DNEasy Tissue Kit (Qiagen) in accordance with the manufacturer's instructions. Primer sets used to amplify the cytb, COI and IRBP genes are listed in Table 2. All amplifications were carried out in $25 \mu \mathrm{L}$ reactions containing about $30 \mathrm{ng}$ of extracted DNA, $0.2 \mathrm{mg} /$ $\mathrm{mL}$ BSA (Roche, $1 \mathrm{mg} / \mathrm{mL}$ ), $300 \mu \mathrm{M}$ of each dNTP, 0.2 $\mu \mathrm{M}$ of each primer, 1 unit of Taq polymerase (Qiagen), 2.5 $\mu \mathrm{L}$ of $10 \mathrm{X}$ buffer, $0.5 \mathrm{mM}$ of extra $\mathrm{MgCl} 2$. Cycling conditions were as follows: one activation step at $94^{\circ} \mathrm{C}$ for 4 min followed by 40 cycles of denaturation at $94^{\circ} \mathrm{C}$ for $30 \mathrm{~s}$, annealing at $48^{\circ} \mathrm{C}-58^{\circ} \mathrm{C}$ depending on the primers (Table 2) for $30 \mathrm{~s}$, elongation at $72^{\circ} \mathrm{C}$ for $45 \mathrm{~s}-1^{\prime} 30$ min depending on the length of the target ( 1 minute per kb), and a final extension at $72^{\circ} \mathrm{C}$ for $10 \mathrm{~min}$. PCR products were sequenced by Macrogen (Seoul, South Korea).

\section{Phylogenetic analyses}

Sequences were aligned by eye using SEAVIEW [41] and translated into peptide sequences using the Transeq EMBOSS tool [42] to exclude putative NUMt copies and to ensure sequence orthology. As the risk of homoplasy by convergence and reversal is reduced by considering a large number of characters [43], we combined the three genes into a single dataset using the DAMBE software [44]. Thus, a total of 3,068 bp were considered in the subsequent phylogenetic analyses.

Base composition bias was evaluated using PAUP* v4.0b10 [45], and a chi-square test was performed to check for taxa with deviations of nucleotide composition. Substitutional saturation was assessed via saturation plots. Using DAMBE [44], the absolute number of transitions was plotted against MLComposite TN93 (TamuraNei Model) distance for all pairwise comparisons of taxa. For the three genes, the curve did not reach a plateau when subtracting the third codon position, but did reach 


\begin{tabular}{|c|c|c|c|c|c|c|c|}
\hline \multicolumn{3}{|l|}{ Sample information } & \multirow[b]{2}{*}{$\begin{array}{l}\text { Voucher } \\
\text { localisation }\end{array}$} & \multirow[b]{2}{*}{$\begin{array}{l}\text { Phylogenetic } \\
\text { species }\end{array}$} & \multicolumn{3}{|c|}{ GenBank Accession Number } \\
\hline $\begin{array}{l}\text { Laboratory sample } \\
\text { number }\end{array}$ & Field Identification & Locality & & & Cyt b & col & IRBP \\
\hline MDZ10Mada & Rattus rattus & Madagascar & & $\mathrm{R} 1$ & HM217368 & HM217495 & HM217603 \\
\hline ratcosT820 & Rattus rattus & India & & R1 & HM217367 & HM217498 & HM217606 \\
\hline ratcosR12 & Rattus rattus & Oman & & R1 & $\underline{\mathrm{HM} 217366}$ & $\underline{\mathrm{HM} 217496}$ & HM217604 \\
\hline ratcosTE4264 & Rattus rattus & Tanzania & & R1 & HM217365 & HM217497 & HM217605 \\
\hline R4003 & Rattus tanezumi & Kalasin (Thailand) & MahaU & R2 & $\underline{\mathrm{HM} 217436}$ & $\underline{\mathrm{HM} 217563}$ & HM217673 \\
\hline R2953 & Rattus tanezumi & Kanchanaburi (Thailand) & & R7 & HM217396 & HM217525 & HM217634 \\
\hline R2996 & Rattus tanezumi & Kanchanaburi (Thailand) & & R2 & $\underline{\mathrm{HM} 217398}$ & $\underline{\mathrm{HM} 217529}$ & HM217636 \\
\hline R3122 & Rattus tanezumi & Kanchanaburi (Thailand) & & R2 & HM217407 & HM217537 & HM217645 \\
\hline R3214 & Rattus tanezumi & Kanchanaburi (Thailand) & & R2 & $\underline{\mathrm{HM} 217410}$ & $\underline{\mathrm{HM} 217540}$ & HM217648 \\
\hline R3573 & Rattus tanezumi & Nakhon Pathom (Thailand) & $\mathrm{KU}$ & R2 & $\underline{\mathrm{HM} 217430}$ & $\underline{\mathrm{HM} 217558}$ & HM217667 \\
\hline R4016 & Rattus tanezumi & Phrae (Thailand) & CBGP & R2 & HM217438 & HM217565 & HM217675 \\
\hline R4424 & Rattus tanezumi & Phrae (Thailand) & MahaU & R2 & $\underline{\mathrm{HM} 217456}$ & $\underline{\mathrm{HM}} 217582$ & $\underline{H M 217693}$ \\
\hline R4436 & Rattus tanezumi & Phrae (Thailand) & MahaU & R2 & HM217457 & $\underline{\mathrm{HM}} 217583$ & HM217694 \\
\hline R5294 & Rattus tanezumi & Nan (Thailand) & MahaU & R2 & HM217466 & HM217592 & HM217704 \\
\hline R5296 & Rattus tanezumi & Nan (Thailand) & CBGP & R2 & $\underline{\mathrm{HM} 217467}$ & $\underline{\mathrm{HM} 217593}$ & $\underline{\mathrm{HM} 217705}$ \\
\hline L0100 & Rattus tanezumi & Luang Prabang (LPDR) & MahaU & R2 & HM217475 & HM217489 & HM217712 \\
\hline L0194 & Rattus tanezumi & Luang Prabang (LPDR) & MahaU & R2 & $\underline{\mathrm{HM} 217480}$ & $\underline{\mathrm{HM} 217494}$ & $\underline{\mathrm{HM} 217717}$ \\
\hline R3029 & Rattus tanezumi & Bangkok (Thailand) & & R3 & HM217399 & HM217530 & HM217637 \\
\hline R1843 & Rattus tanezumi & Krabi (Thailand) & & R3 & HM217393 & HM217524 & HM217631 \\
\hline R1147 & Rattus tanezumi & Nakhon Ratchasima (Thailand) & & R3 & HM217384 & $\underline{\mathrm{HM} 217515}$ & HM217622 \\
\hline R1016 & Rattus tanezumi & Nakhon Ratchasima (Thailand) & & R3 & HM217382 & $\underline{\mathrm{HM}} 217513$ & HM217620 \\
\hline R1818 & Rattus tanezumi & Prachinburi (Thailand) & & R3 & HM217389 & HM217520 & HM217627 \\
\hline R2794 & Rattus tanezumi & Ratchaburi (Thailand) & & R3 & HM217394 & HM217526 & HM217632 \\
\hline R0169 & Rattus tanezumi & Ratchaburi (Thailand) & & R3 & HM217372 & HM217503 & HM217610 \\
\hline СВ0028 & Rattus tanezumi & Veal Renh (Cambodia) & MahaU & R3 & $\underline{\mathrm{HM} 217363}$ & $\underline{\mathrm{HM} 217485}$ & HM217601 \\
\hline R1833 & Rattus tanezumi & Nakhon Sri Thammarat (Thailand) & & R5 & HM217391 & HM217522 & HM217629 \\
\hline
\end{tabular}




\begin{tabular}{|c|c|c|c|c|c|c|c|}
\hline R4402 & Rattus losea & Loei (Thailand) & MahaU & R4 & $\underline{\mathrm{HM} 217454}$ & $\underline{\mathrm{HM} 217581}$ & $\underline{\mathrm{HM} 217691}$ \\
\hline R3484 & Rattus losea & Loei (Thailand) & & R4 & $\underline{\mathrm{HM}} 217421$ & $\underline{\mathrm{HM} 217550}$ & $\underline{\mathrm{HM} 217659}$ \\
\hline R4230 & Rattus losea & Loei (Thailand) & CBGP & R4 & $\underline{\mathrm{HM} 217446}$ & $\underline{\mathrm{HM} 217573}$ & $\underline{\mathrm{HM} 217683}$ \\
\hline R1015 & Rattus losea & Nakhon Ratchasima (Thailand) & & R4 & $\underline{\mathrm{HM} 217381}$ & $\underline{\mathrm{HM}} 217512$ & $\underline{\mathrm{HM} 217619}$ \\
\hline R4203 & Rattus losea & Phrae (Thailand) & CBGP & R4 & $\underline{\mathrm{HM}} 217443$ & $\underline{\mathrm{HM} 217570}$ & $\underline{\mathrm{HM} 217680}$ \\
\hline R3510 & Rattus losea & Phrae (Thailand) & & R4 & $\underline{\mathrm{HM}} 217423$ & $\underline{\mathrm{HM} 217552}$ & $\underline{\mathrm{HM} 217661}$ \\
\hline R0237 & Rattus losea & Ratchaburi (Thailand) & & R4 & $\underline{\mathrm{HM}} 217374$ & $\underline{\mathrm{HM} 217505}$ & $\underline{\mathrm{HM}} 217612$ \\
\hline R0238 & Rattus losea & Ratchaburi (Thailand) & & R4 & $\underline{\mathrm{HM} 217375}$ & $\underline{\mathrm{HM} 217506}$ & $\underline{\mathrm{HM} 217613}$ \\
\hline $\mathrm{R} 1805$ & Rattus exulans & Bangkok (Thailand) & & R8 & $\underline{\mathrm{HM} 217388}$ & $\underline{\mathrm{HM} 217519}$ & $\underline{\mathrm{HM}} 217626$ \\
\hline R4004 & Rattus exulans & Kalasin (Thailand) & MahaU & R8 & $\underline{\mathrm{HM} 217437}$ & $\underline{\mathrm{HM} 217564}$ & $\underline{\mathrm{HM} 217674}$ \\
\hline R3224 & Rattus exulans & Kanchanaburi (Thailand) & & R8 & $\underline{\mathrm{HM}} 217411$ & $\underline{\mathrm{HM}} 217541$ & $\underline{\mathrm{HM} 217649}$ \\
\hline R4103 & Rattus exulans & Loei (Thailand) & MahaU & R8 & $\underline{\mathrm{HM} 217440}$ & $\underline{\mathrm{HM}} 217567$ & HM217677 \\
\hline R1055 & Rattus exulans & Nakhon Ratchasima (Thailand) & & R8 & $\underline{\mathrm{HM}} 217383$ & $\underline{\mathrm{HM}} 217514$ & HM217621 \\
\hline R1836 & Rattus exulans & Nakhon Sri Thammarat (Thailand) & & R8 & $\underline{\mathrm{HM}} 217392$ & $\underline{\mathrm{HM} 217523}$ & $\underline{\mathrm{HM} 217630}$ \\
\hline R4140 & Rattus exulans & Phrae (Thailand) & MahaU & $\mathrm{R} 8$ & $\underline{\mathrm{HM} 217441}$ & HM217568 & $\underline{\mathrm{HM} 217678}$ \\
\hline R0284 & Rattus exulans & Ratchaburi (Thailand) & & R8 & $\underline{\mathrm{HM}} 217377$ & $\underline{\mathrm{HM} 217508}$ & $\underline{\mathrm{HM} 217615}$ \\
\hline R2795 & Rattus exulans & Ratchaburi (Thailand) & & R8 & $\underline{\mathrm{HM} 217395}$ & $\underline{\mathrm{HM}} 217527$ & $\underline{\mathrm{HM} 217633}$ \\
\hline R3520 & Rattus exulans & Sakhon Nakhon (Thailand) & MahiU & R8 & $\underline{\mathrm{HM}} 217424$ & $\underline{\mathrm{HM}} 217553$ & $\underline{\mathrm{HM} 217662}$ \\
\hline R3563 & Rattus exulans & Surat Thani (Thailand) & $\mathrm{KU}$ & R8 & $\underline{\mathrm{HM}} 217428$ & $\underline{\mathrm{HM}} 217557$ & $\underline{\mathrm{HM} 217666}$ \\
\hline R5349 & Rattus exulans & Nan (Thailand) & CBGP & $\mathrm{R} 8$ & $\underline{\mathrm{HM}} 217470$ & $\underline{\mathrm{HM} 217595}$ & $\underline{\mathrm{HM} 217703}$ \\
\hline R5447 & Rattus exulans & Nan (Thailand) & CBGP & R8 & $\underline{\mathrm{HM} 217472}$ & $\underline{\mathrm{HM} 217596}$ & $\underline{\mathrm{HM} 217708}$ \\
\hline СВ0001 & Rattus argentiventer & Veal Renh (Cambodia) & MahaU & R6 & $\underline{\mathrm{HM}} 217362$ & $\underline{\mathrm{HM}} 217484$ & HM217600 \\
\hline CB0104 & Rattus argentiventer & Veal Renh (Cambodia) & MahaU & R6 & $\underline{\mathrm{HM} 217364}$ & $\underline{\mathrm{HM} 217486}$ & $\underline{\mathrm{HM} 217602}$ \\
\hline R3087 & Rattus andamanensis & Kanchanaburi (Thailand) & & $\mathrm{R} 7$ & $\underline{\mathrm{HM}} 217403$ & $\underline{\mathrm{HM}} 217533$ & $\underline{\mathrm{HM} 217641}$ \\
\hline R4377 & Rattus andamanensis & Loei (Thailand) & MahaU & $\mathrm{R} 2$ & $\underline{\mathrm{HM}} 217452$ & $\underline{\mathrm{HM} 217579}$ & $\underline{H M} 217689$ \\
\hline R3548 & Rattus andamanensis & Phrae (Thailand) & $\mathrm{KU}$ & $\mathrm{R} 2$ & $\underline{\mathrm{HM}} 217426$ & $\underline{\mathrm{HM}} 217555$ & HM217664 \\
\hline R4481 & Rattus andamanensis & Phrae (Thailand) & MahaU & $\mathrm{R} 2$ & $\underline{\mathrm{HM}} 217458$ & $\underline{\mathrm{HM}} 217584$ & $\underline{\mathrm{HM}} 217695$ \\
\hline R0130 & Rattus andamanensis & Ratchaburi (Thailand) & & $\mathrm{R} 2$ & $\underline{\mathrm{HM} 217371}$ & $\underline{\mathrm{H} M 217502}$ & $\underline{\mathrm{HM} 217608}$ \\
\hline R2976 & Rattus andamanensis & Nakhon Pathom (Thailand) & & R3 & $\underline{\mathrm{HM} 217397}$ & $\underline{\mathrm{HM} 217528}$ & $\underline{\mathrm{HM} 217635}$ \\
\hline
\end{tabular}


Table 1: Samples used in this study. (Continued)

\begin{tabular}{|c|c|c|c|c|c|c|c|}
\hline R3565 & Rattus norvegicus & Nakhon Pathom (Thailand) & MahiU & R9 & $\underline{\mathrm{HM} 217429}$ & - & - \\
\hline R0223 & Rattus norvegicus & Ratchaburi (Thailand) & & R9 & $\underline{\mathrm{HM} 217373}$ & $\underline{\mathrm{HM} 217504}$ & $\underline{\mathrm{HM} 217611}$ \\
\hline R0115 & Rattus norvegicus & Ratchaburi (Thailand) & & R9 & $\underline{\mathrm{HM} 217370}$ & $\underline{\mathrm{HM} 217501}$ & HM217609 \\
\hline RNO 032 & Rattus norvegicus & Cambodia & & R9 & $\underline{\mathrm{HM} 217481}$ & $\underline{\mathrm{HM} 217499}$ & - \\
\hline L0180 & Rattus nitidus & Luang Prabang (LPDR) & MahaU & R10 & $\underline{\mathrm{HM} 217478}$ & $\underline{\mathrm{HM} 217492}$ & $\underline{\mathrm{HM} 217715}$ \\
\hline L0192 & Rattus nitidus & Luang Prabang (LPDR) & MahaU & R10 & $\underline{\mathrm{HM} 217479}$ & $\underline{\mathrm{HM} 217493}$ & $\underline{\mathrm{HM} 217716}$ \\
\hline R4188 & Rattus sp. & Phrae (Thailand) & CBGP & R3 & $\underline{\mathrm{HM}} 217442$ & $\underline{\mathrm{HM}} 217569$ & HM217679 \\
\hline L0010 & Rattus sp. & Luang Prabang (LPDR) & MahaU & R10 & $\underline{\mathrm{HM} 217474}$ & $\underline{\mathrm{HM} 217488}$ & $\underline{\mathrm{HM} 217711}$ \\
\hline R0856 & Bandicota indica & Nakhon Pathom (Thailand) & & R8 & $\underline{\mathrm{HM} 217379}$ & $\underline{\mathrm{HM} 217510}$ & $\underline{\mathrm{HM} 217617}$ \\
\hline R4001 & Bandicota indica & Kalasin (Thailand) & MahaU & B1 & $\underline{\mathrm{HM} 217435}$ & - & $\underline{\mathrm{HM} 217672}$ \\
\hline R3189 & Bandicota indica & Kanchanaburi (Thailand) & & B1 & $\underline{\mathrm{HM} 217408}$ & $\underline{\mathrm{HM} 217538}$ & $\underline{\mathrm{HM} 217646}$ \\
\hline R4265 & Bandicota indica & Loei (Thailand) & CBGP & B1 & $\underline{\mathrm{HM}} 217447$ & $\underline{\mathrm{HM}} 217574$ & HM217684 \\
\hline R1006 & Bandicota indica & Nakhon Ratchasima (Thailand) & & B1 & $\underline{\mathrm{HM} 217380}$ & $\underline{\mathrm{HM} 217511}$ & $\underline{\mathrm{HM} 217618}$ \\
\hline R3521 & Bandicota indica & Phrae (Thailand) & $\mathrm{KU}$ & B1 & $\underline{\mathrm{HM} 217425}$ & $\underline{\mathrm{HM} 217554}$ & $\underline{\mathrm{HM} 217663}$ \\
\hline R0269 & Bandicota indica & Ratchaburi (Thailand) & & B1 & $\underline{\mathrm{HM} 217376}$ & $\underline{\mathrm{HM}} 217507$ & $\underline{\mathrm{HM}} 217614$ \\
\hline R0304 & Bandicota indica & Ratchaburi (Thailand) & & B1 & $\underline{\mathrm{HM}} 217378$ & $\underline{\mathrm{HM} 217509}$ & $\underline{\mathrm{HM} 217616}$ \\
\hline R5313 & Bandicota indica & Nan (Thailand) & MahaU & B1 & $\underline{\mathrm{HM}} 217469$ & $\underline{\mathrm{HM} 217594}$ & $\underline{\mathrm{HM} 217706}$ \\
\hline L0142 & Bandicota indica & Luang Prabang (LPDR) & MahaU & B1 & $\underline{\mathrm{HM} 217476}$ & $\underline{\mathrm{HM} 217490}$ & $\underline{\mathrm{HM} 217713}$ \\
\hline R4408 & Bandicota indica & Loei (Thailand) & CBGP & B2 & $\underline{\mathrm{HM} 217455}$ & - & $\underline{\mathrm{HM} 217692}$ \\
\hline R1284 & Bandicota savilei & Nakhon Ratchasima (Thailand) & & B1 & $\underline{\mathrm{HM} 217386}$ & $\underline{\mathrm{HM}} 217517$ & $\underline{\mathrm{HM}} 217624$ \\
\hline R1822 & Bandicota savilei & Nakhon Pathom (Thailand) & & B1 & $\underline{\mathrm{HM}} 217390$ & $\underline{\mathrm{HM}} 217521$ & HM217628 \\
\hline R1797 & Bandicota savilei & Kanchanaburi (Thailand) & & B2 & $\underline{\mathrm{HM}} 217387$ & $\underline{\mathrm{HM}} 217518$ & HM217625 \\
\hline R1191 & Bandicota savilei & Nakhon Ratchasima (Thailand) & & B2 & $\underline{\mathrm{HM} 217385}$ & $\underline{\mathrm{HM} 217516}$ & $\underline{\mathrm{HM} 217623}$ \\
\hline R3550 & Bandicota savilei & Phrae (Thailand) & $\mathrm{KU}$ & B2 & $\underline{\mathrm{HM}} 217427$ & $\underline{\mathrm{HM} 217556}$ & $\underline{\mathrm{HM} 217665}$ \\
\hline R0093 & Bandicota sp. & Ratchaburi (Thailand) & & B2 & $\underline{\mathrm{HM} 217369}$ & $\underline{\mathrm{HM} 217500}$ & $\underline{\mathrm{HM} 217607}$ \\
\hline R3050 & Berylmys berdmorei & Kanchanaburi (Thailand) & & Be1 & $\underline{\mathrm{HM}} 217401$ & $\underline{\mathrm{HM} 217532}$ & HM217639 \\
\hline R4266 & Berylmys berdmorei & Loei (Thailand) & CBGP & $\mathrm{Be} 1$ & $\underline{\mathrm{HM}} 217448$ & $\underline{\mathrm{HM} 217575}$ & HM217685 \\
\hline R3441 & Berylmys berdmorei & Loei (Thailand) & MahiU & Be1 & HM217418 & HM217547 & HM217656 \\
\hline
\end{tabular}


Table 1: Samples used in this study. (Continued)

\begin{tabular}{|c|c|c|c|c|c|c|c|}
\hline R5310 & Berylmys berdmorei & Nan (Thailand) & MahaU & Be1 & $\underline{\mathrm{HM} 217468}$ & - & $\underline{\mathrm{HM} 217709}$ \\
\hline L0006 & Berylmys berdmorei & Luang Prabang (LPDR) & MahaU & $\mathrm{Be} 1$ & $\underline{\mathrm{HM} 217473}$ & $\underline{\mathrm{HM} 217487}$ & $\underline{\mathrm{HM} 217710}$ \\
\hline R3618 & Berylmys berdmorei & Phrae (Thailand) & $\mathrm{KU}$ & $\mathrm{Be} 1$ & $\underline{\mathrm{HM} 217432}$ & $\underline{\mathrm{HM} 217560}$ & $\underline{\mathrm{HM} 217669}$ \\
\hline R3603 & Berylmys berdmorei & Phrae (Thailand) & $\mathrm{KU}$ & $\mathrm{Be} 1$ & $\underline{\mathrm{HM} 217431}$ & $\underline{\mathrm{HM} 217559}$ & $\underline{\mathrm{HM} 217668}$ \\
\hline R4400 & Berylmys bowersi & Loei (Thailand) & MahaU & $\mathrm{Be} 2, \mathrm{a}$ & $\underline{\mathrm{HM}} 217453$ & $\underline{\mathrm{HM} 217580}$ & $\underline{\mathrm{HM}} 217690$ \\
\hline R3425 & Berylmys bowersi & Loei (Thailand) & $\mathrm{KU}$ & $\mathrm{Be} 2, \mathrm{a}$ & $\underline{\mathrm{HM} 217415}$ & $\underline{\mathrm{HM} 217544}$ & $\underline{\mathrm{HM} 217653}$ \\
\hline R3415 & Berylmys bowersi & Loei (Thailand) & $\mathrm{KU}$ & $\mathrm{Be} 2, \mathrm{a}$ & $\underline{\mathrm{HM} 217413}$ & $\underline{\mathrm{HM} 217542}$ & $\underline{\mathrm{HM} 217651}$ \\
\hline R5410 & Berylmys bowersi & Nan (Thailand) & MahaU & $\mathrm{Be} 2, \mathrm{a}$ & $\underline{\mathrm{HM} 217471}$ & - & $\underline{\mathrm{HM} 217707}$ \\
\hline L0151 & Berylmys bowersi & Luang Prabang (LPDR) & MahaU & $\mathrm{Be} 2, \mathrm{a}$ & $\underline{\mathrm{HM} 217477}$ & $\underline{\mathrm{HM} 217491}$ & $\underline{\mathrm{HM} 217714}$ \\
\hline R3268 & Berylmys bowersi & Kanchanaburi (Thailand) & $\mathrm{KU}$ & $\mathrm{Be} 2, \mathrm{~b}$ & HM217412 & HM217597 & HM217650 \\
\hline R4098 & Leopoldamys sabanus & Loei (Thailand) & CBGP & L1 & $\underline{\mathrm{HM} 217439}$ & $\underline{\mathrm{HM} 217566}$ & $\underline{\mathrm{HM} 217676}$ \\
\hline R4222 & Leopoldamys sabanus & Loei (Thailand) & MahaU & L1 & $\underline{\mathrm{HM} 217444}$ & $\underline{\mathrm{HM}} 217571$ & $\underline{\mathrm{HM}} 217681$ \\
\hline R4296 & Leopoldamys sabanus & Phrae (Thailand) & MahaU & L1 & $\underline{\mathrm{HM} 217450}$ & $\underline{\mathrm{HM} 217577}$ & $\underline{\mathrm{HM} 217687}$ \\
\hline R4276 & Leopoldamys sabanus & Phrae (Thailand) & CBGP & L1 & $\underline{\mathrm{HM} 217449}$ & $\underline{\mathrm{HM} 217576}$ & $\underline{\mathrm{HM} 217686}$ \\
\hline R4370 & Leopoldamys sabanus & Phrae (Thailand) & CBGP & L1 & $\underline{\mathrm{HM} 217451}$ & $\underline{\mathrm{HM}} 217578$ & $\underline{\mathrm{HM} 217688}$ \\
\hline R3111 & Leopoldamys sabanus & Kanchanaburi (Thailand) & & L3 & $\underline{\mathrm{HM}} 217404$ & $\underline{\mathrm{HM}} 217534$ & $\underline{\mathrm{HM}} 217642$ \\
\hline R3033 & Leopoldamys sabanus & Kanchanaburi (Thailand) & & L3 & $\underline{\mathrm{HM} 217400}$ & $\underline{\mathrm{HM} 217531}$ & $\underline{\mathrm{HM} 217638}$ \\
\hline R4517 & Leopoldamys neilli & Loei (Thailand) & MahaU & L2 & $\underline{\mathrm{HM}} 217462$ & $\underline{\mathrm{HM} 217588}$ & $\underline{\mathrm{HM} 217699}$ \\
\hline R4527 & Leopoldamys neilli & Loei (Thailand) & MahaU & L2 & $\underline{\mathrm{HM} 217463}$ & $\underline{\mathrm{HM} 217590}$ & $\underline{\mathrm{HM}} 217701$ \\
\hline R4486 & Leopoldamys neilli & Phrae (Thailand) & MahaU & L2 & $\underline{\mathrm{HM} 217460}$ & $\underline{\mathrm{HM} 217586}$ & $\underline{\mathrm{HM} 217697}$ \\
\hline R4485 & Leopoldamys neilli & Phrae (Thailand) & MahaU & L2 & $\underline{\mathrm{HM} 217459}$ & $\underline{\mathrm{HM} 217585}$ & $\underline{\mathrm{HM}} 217696$ \\
\hline R3419 & Leopoldamys sp. & Loei (Thailand) & $\mathrm{KU}$ & L1 & $\underline{\mathrm{HM} 217414}$ & $\underline{\mathrm{HM} 217543}$ & $\underline{\mathrm{HM}} 217652$ \\
\hline R4723 & Niviventer fulvescens & Loei (Thailand) & MahaU & N1 & $\underline{\mathrm{HM} 217465}$ & $\underline{\mathrm{HM} 217591}$ & $\underline{\mathrm{HM}} 217702$ \\
\hline R3212 & Niviventer fulvescens & Kanchanaburi (Thailand) & $\mathrm{KU}$ & $\mathrm{N} 2$ & $\underline{\mathrm{HM} 217409}$ & $\underline{\mathrm{HM} 217539}$ & $\underline{\mathrm{HM}} 217647$ \\
\hline R4525 & Niviventer sp. & Loei (Thailand) & MahaU & N1 & $\underline{\mathrm{HM} 217464}$ & $\underline{\mathrm{HM} 217589}$ & $\underline{\mathrm{HM}} 217700$ \\
\hline R3427 & Niviventer sp. & Loei (Thailand) & $\mathrm{KU}$ & N1 & $\underline{\mathrm{HM} 217416}$ & $\underline{\mathrm{HM} 217545}$ & $\underline{\mathrm{HM}} 217654$ \\
\hline R3429 & Niviventer sp. & Loei (Thailand) & KU & N1 & $\underline{\mathrm{HM}} 217417$ & $\underline{\mathrm{HM} 217546}$ & $\underline{\mathrm{HM}} 217655$ \\
\hline
\end{tabular}


Table 1: Samples used in this study. (Continued)

\begin{tabular}{|c|c|c|c|c|c|c|c|}
\hline R3459 & Niviventer sp. & Loei (Thailand) & KU & N1 & $\underline{\mathrm{HM} 217419}$ & HM217548 & $\underline{\mathrm{HM} 217657}$ \\
\hline R4497 & Niviventer sp. & Phrae (Thailand) & MahaU & $\mathrm{N} 1$ & $\underline{\mathrm{HM} 217461}$ & $\underline{\text { HM217587 }}$ & $\underline{\mathrm{HM} 217698}$ \\
\hline R3492 & Niviventer $s p$. & Loei (Thailand) & $\mathrm{KU}$ & N1 & HM217422 & HM217551 & HM217660 \\
\hline R3077 & Niviventer sp. & Kanchanaburi (Thailand) & MahiU & N3 & $\underline{\mathrm{HM} 217402}$ & - & $\underline{\mathrm{HM} 217640}$ \\
\hline R3795 & Nu Deng* & Khammouane (LPDR) & MahiU & N4 & $\underline{\mathrm{HM} 217433}$ & $\underline{\mathrm{HM} 217561}$ & $\underline{\mathrm{HM} 217670}$ \\
\hline R3796 & Nu Deng* & Khammouane (LPDR) & MahiU & N4 & $\underline{\mathrm{HM} 217434}$ & $\underline{\mathrm{HM} 217562}$ & $\underline{\mathrm{HM} 217671}$ \\
\hline R3118 & Maxomys surifer & Kanchanaburi (Thailand) & & M1 & $\underline{\mathrm{HM} 217406}$ & $\underline{H M 217536}$ & $\underline{\mathrm{HM} 217644}$ \\
\hline R3116 & Maxomys surifer & Kanchanaburi (Thailand) & & M1 & $\underline{\mathrm{HM} 217405}$ & $\underline{\mathrm{HM} 217535}$ & $\underline{\mathrm{HM} 217643}$ \\
\hline R4223 & Maxomys surifer & Loei (Thailand) & CBGP & M2 & $\underline{\mathrm{HM}} 217445$ & HM217572 & $\underline{\mathrm{HM}} 217682$ \\
\hline R3464 & Maxomys surifer & Loei (Thailand) & $\mathrm{KU}$ & M2 & $\underline{\mathrm{HM} 217420}$ & $\underline{\mathrm{HM} 217549}$ & $\underline{\mathrm{HM} 217658}$ \\
\hline MK0509 BZ02 & Micromys minutus & China & CBGP & Outgroup & $\underline{\mathrm{HM} 217360}$ & HM217482 & $\underline{\mathrm{HM} 217598}$ \\
\hline MK0509 BZ07 & Micromys minutus & China & CBGP & Outgroup & HM217361 & $\underline{\mathrm{HM} 217483}$ & HM217599 \\
\hline
\end{tabular}

Field identifications were achieved based on morphological criteria according to [33-35] and [11]

"Phylogenetic species" relies on the DNA-based species delimitation method (see also Figure 3).

Mismatches between field identifications and phylogenetic species are highlighted in bold and reflect the difficulty to identify rat species even for experts.

"Nu deng*" was assigned to animal identified but impossible to assigned to a particular species; in Thai language, "red rat".

"-" corresponds to missing data in the phylogenetic analyses.

Voucher locations:

CBGP: Centre de Biologie et de Gestion des Populations, Montpellier, France - curator of the collections, Y. Chaval,

chaval@supagro.inra.fr

/KU: Kasetsart University, Bangkok, Thailand - curator: W. Rerkamnuaychoke/MahiU: Mahidol University, Nakhon Pathom, Thailand - curator: V. Herbreteau,

MahaU: Mahasarakham University, Mahasarakham, Thailand - curator: S. Soonchan

See Figure 1 for additional information about sample locations. 


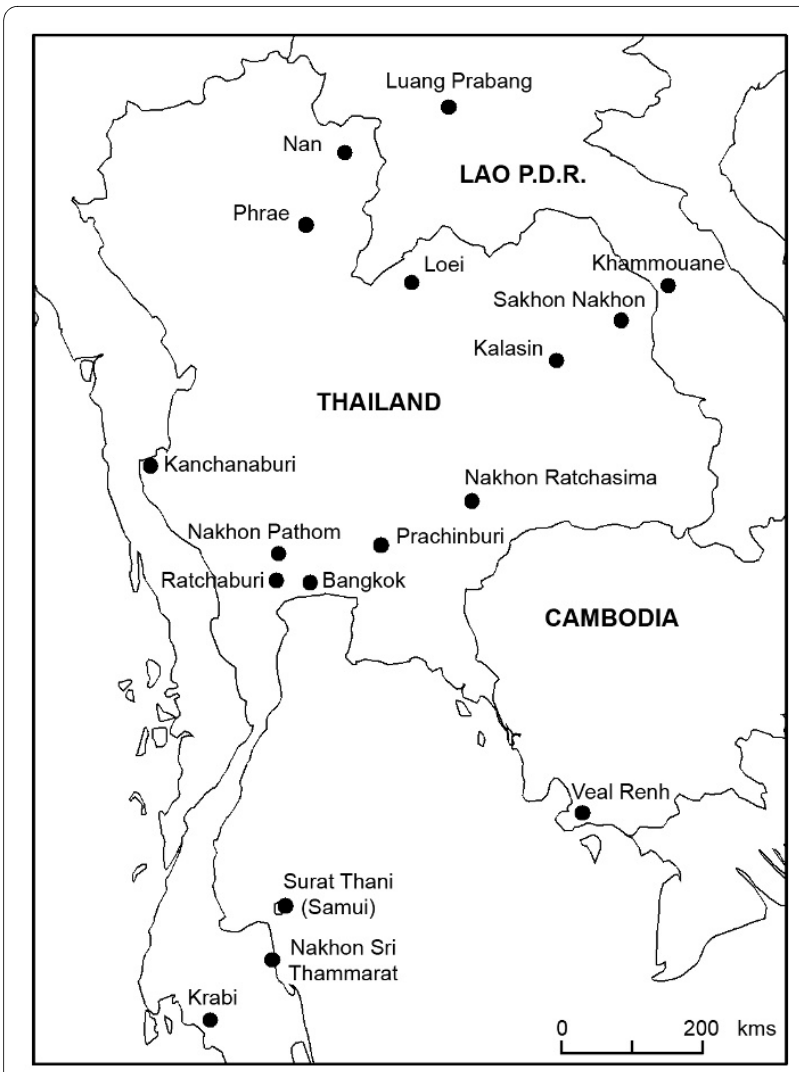

Figure 1 Sample locations of the Rattini specimens caught in the field and included in this study. See Table 1 for more sample information.

a plateau when considering the entire sequences (data not shown). To discard fast evolving transitions and improve inferences without drastically compromising the resolution, we decided to recode the third codon position nucleotides to two state categories, $\mathrm{R}$ (purine) and $\mathrm{Y}$ (pyrimidine), (RY-coding strategy; [46]).

Phylogenetic trees were reconstructed using two probabilistic approaches: maximum likelihood (ML) and Bayesian inferences (BI). The appropriate model of evolution was first determined for each gene and for the concatenated dataset (with and without RY-coding) using corrected Akaike information criterion (AICc) and MrAIC [47]. The HKY $+\mathrm{I}+\Gamma$ model was selected for both the cytb and COI genes while the GTR $+\Gamma$ was selected for the IRBP gene and the combined dataset (with and without RY-coding). ML analyses were performed with PhyML-v2.4.4 [48]. For each analysis, the transition/ transversion ratio, the proportion of invariable sites as well as the gamma distribution parameter (if necessary) were estimated and the starting tree was determined by BioNJ analysis of the dataset (default settings). Using optimization options, 500 bootstrap (Bp) replicates were performed. PhyML analyses were first run independently on each locus and then on the combined dataset (with and without RY-coding). Taking into account that PhyML does not allow data-partitioning, partitioned ML analysis was also performed using RAxML 7.0.4 [49]. As the model choice is limited in RAxML, the general timereversible (GTR) $+\Gamma$ model (option -m GTRGAMMA) was selected for the three partitions (option -q multipleModelFileName), and individual $\alpha$-shape parameters, GTR-rates and base frequencies were estimated and optimized for each partition. Robustness of the tree was assessed using the rapid bootstrap procedure (option -f a) with 100 replications (option -\# numberOfRuns) [50].

Bayesian analyses were performed using MrBayes v3.1 [51]. Four independent runs of 5,000,000 generations each were performed applying appropriate independent models of evolution to each gene. A burn-in period of $1,000,000$ generations was determined graphically using Tracer1.2 [52]. For each dataset, all runs gave similar tree topologies and posterior probability (pp) values.

Alternative topologies were finally tested for significance using the Shimodaira-Hasegawa test (SH test) [53] (RELL option, 1000 Bp replicates) in PAUP* v4.0b10 [45].

\section{Species delimitation: DNA-based species delimitation method}

We used the DNA-based approach proposed by Pons et al. [28]. Using a likelihood framework, this new procedure detects the switch in the rate of lineage branching of a tree from interspecific long branches to intraspecific short budding branching and identifies clusters of specimens corresponding to putative species. Two models are implemented to account for the branching process of the entire tree. Under the null model, the whole sample derives from a single population obeying a coalescent process. The alternative model, called general mixed Yule coalescent (GMYC) model combines equations that separately describe branching within populations (coalescent process) and branching between species (a Yule model including speciation and extinction rates). Under the GMYC model, a threshold (T) is optimized such that nodes before the threshold are considered as species diversification events, whereas branches crossing the threshold define clusters following a coalescent process. A standard likelihood ratio test (LRT) is used to assess whether the alternative model provides a better fit than the null model. If the GMYC model is favoured over the null model, the $\mathrm{T}$ parameter of the maximum likelihood solution allows the number of species to be estimated. This test was achieved using the R code provided by T. G. Barraclough. This latest version outputs the estimates of the number of species, of the threshold time and their $95 \%$ confidence limits (i.e. solutions with 2-log likelihood units of the maximum).

Because a pre-requisite of the method is an ultrametric tree, we used the relaxed Bayesian dating method imple- 
Table 2: Primers and PCR cycling conditions used in this study.

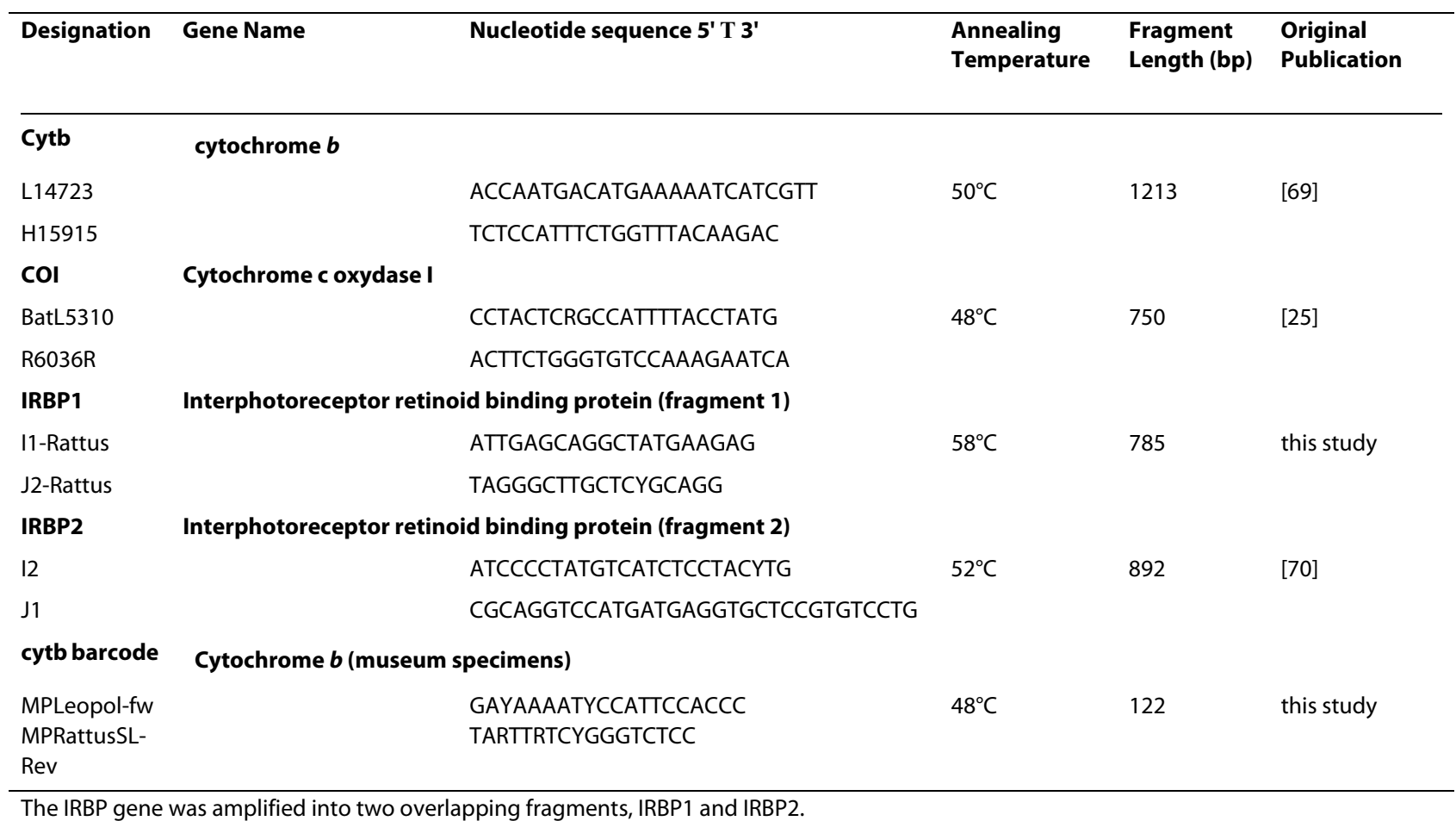

mented in Multidivtime [54] to convert our optimal phylogram tree (estimated from the Bayesian analysis of the combined dataset) in a rooted additive tree with terminal nodes equally distant to the root. In this aim, we followed the documentation files written by Rutschmann [55] and the procedure detailed in [29]. The settings for the Markov chain Monte Carlo analyses were slightly modified (200,000 cycles in which the Markov chain was sampled 20,000 times every $10^{\text {th }}$ cycle following a burnin period of 100,000 cycles). No fossil is described to calibrate our Rattini phylogeny. As our aim was simply to obtain an ultrametric tree, prior ages to lineages were arbitrarily assigned to $1(\mathrm{rttm}=1 ; \mathrm{rttmsd}=0)$. The mean of the prior distribution for the rate of molecular evolution at the ingroup root node (rtrate) was computed as the mean of the median of the amount of evolution for the different tips of the three independent gene trees $($ rtrate $=0.735 ;$ rtratesd $=0.367)$.

\section{Species identification}

\subsection{Within the Rattus genus}

Rattus cytb (663 bp) and COI (655 bp) sequences obtained by Robins et al. [25] were extracted from GenBank and added to our mitochondrial $(m t)$ dataset (see Table 3). As our study focuses on rodents from the Indochinese region, sequences of species belonging to the Rattus fuscipes species group (i.e. native Australian species) and to the Rattus leucopus species group (i.e. species indigenous to New Guinea and adjacent archipelagos) were not incorporated in this dataset. Two other unpublished cytb sequences of $R$. argentiventer and $R$. sikkimensis (synonym of $R$. andamanensis) provided by $\mathrm{O}$. Verneau and F. Catzeflis were also included in the subsequent analysis. Sequences of a single representative of Berylmys, Niviventer, Leopoldamys, Maxomys and Micromys were used to root our mitochondrial phylogeny. Therefore, the $m t$ dataset included 129 sequences corresponding to 1,318 bp of $m t$ DNA. Partitioned ML analysis was performed using RAxML 7.0.4 [49] and the same options as before.

\subsection{Ancient DNA analysis of a holotype specimen}

For species assignment, we tested the relevance of DNA sequences obtained from a holotype specimen. As museum samples contain tiny amounts of poorly preserved DNA, we selected a 85 bp fragment of the cytb gene, corresponding to positions from 666 to 750 of the gene sequence of Rattus norvegicus (NCBI accession number [GenBank NC_001665]). This fragment was chosen for the following reasons: i) it corresponds to an highly variable region of the gene that allows the discrimination of most vertebrate species including the closest related ones [56] ii) its short length is suited for the PCR amplification of degraded DNA [56] and iii) it has proved valuable for species assignment based on degraded DNA extracted from archaeological samples [57]. 
Table 3: Sequences from previous studies included in the $m \boldsymbol{t}$ dataset.

\begin{tabular}{|c|c|c|c|c|c|}
\hline Voucher & Nominal species & Origin of specimen & Cytb & COI & $\begin{array}{l}\text { Phylogenetic } \\
\text { species }\end{array}$ \\
\hline RrSamoa2 & R. rattus & Samoa & [GenBank: EF186475] & [GenBank: EF186590] & $\mathrm{R} 1$ \\
\hline RrRa18 & R. rattus & Raiatea, Society Islands & [GenBank: EF186474] & [GenBank: EF186589] & $\mathrm{R} 1$ \\
\hline ABTC64906 & R. rattus diardi (1) & Kuala Lumpur, Malaysia & [GenBank: EF186413] & [GenBank: EF186528] & $\mathbf{R 3}$ \\
\hline ABTC64907 & R. rattus diardi & Kuala Lumpur, Malaysia & [GenBank: EF186409] & [GenBank: EF186524] & R3 \\
\hline АВTC64908 & R. rattus diardi & Kuala Lumpur, Malaysia & [GenBank: EF186410] & [GenBank: EF186525] & $\mathbf{R 3}$ \\
\hline АВTC64909 & R. rattus diardi & Kuala Lumpur, Malaysia & [GenBank: EF186411] & [GenBank: EF186526] & $\mathbf{R 3}$ \\
\hline ABTC 8529 & R. kandianus (2) & Sri Lanka & [GenBank: EF186444] & [GenBank: EF18655] & $\mathbf{R 3}$ \\
\hline ABTC 8536 & R. kandianus & Sri Lanka & [GenBank: EF186445] & [GenBank: EF186560] & R3 \\
\hline ABTC 8540 & R. kandianus & Sri Lanka & [GenBank: EF186446] & [GenBank: EF186561] & R3 \\
\hline ABTC 8487 & R. tanezumi & Amami Island, Japan & [GenBank: EF186508] & [GenBank: EF186623] & $\mathrm{R} 2$ \\
\hline ABTC 8562 & R. tanezumi & Amami Island, Japan & [GenBank: EF186510] & [GenBank: EF186625] & $\mathrm{R} 2$ \\
\hline ABTC47981 & R. tanezumi & Yogyakarta, Indonesia & [GenBank: EF186493] & [GenBank: EF186608] & $\mathrm{R} 2$ \\
\hline АВTC47982 & R. tanezumi & Yogyakarta, Indonesia & [GenBank: EF186494] & [GenBank: EF186609] & $\mathrm{R} 2$ \\
\hline ABTC47983 & R. tanezumi & Yogyakarta, Indonesia & [GenBank: EF186495] & [GenBank: EF186610] & $\mathrm{R} 2$ \\
\hline АВTC47986 & R. tanezumi & Yogyakarta, Indonesia & [GenBank: EF186504] & [GenBank: EF186619] & $\mathrm{R} 2$ \\
\hline ABTC47987 & R. tanezumi & Yogyakarta, Indonesia & [GenBank: EF186505] & [GenBank: EF186620] & $\mathrm{R} 2$ \\
\hline АВTC47988 & R. tanezumi & Yogyakarta, Indonesia & [GenBank: EF186506] & [GenBank: EF186621] & $\mathbf{R 3}$ \\
\hline АВТС 47989 & R. tanezumi & Yogyakarta, Indonesia & [GenBank: EF186507] & [GenBank: EF186622] & $\mathrm{R} 2$ \\
\hline ABTC47992 & R. tanezumi & Jakarta, Indonesia & [GenBank: EF186490] & [GenBank: EF186605] & R3 \\
\hline АВТС 47993 & R. tanezumi & Jakarta, Indonesia & [GenBank: EF186491] & [GenBank: EF186606] & $\mathrm{R} 2$ \\
\hline АВTC47994 & R. tanezumi & Jakarta, Indonesia & [GenBank: EF186492] & [GenBank: EF186607] & $\mathbf{R 5}$ \\
\hline ABTC47995 & R. tanezumi & Jakarta, Indonesia & [GenBank: EF186496] & [GenBank: EF186611] & $\mathbf{R 3}$ \\
\hline АВTC47996 & R. tanezumi & Jakarta, Indonesia & [GenBank: EF186497] & [GenBank: EF186612] & $\mathbf{R 3}$ \\
\hline АВTC47997 & R. tanezumi & Jakarta, Indonesia & [GenBank: EF186498] & [GenBank: EF186613] & $\mathbf{R 3}$ \\
\hline ABTC47998 & R. tanezumi & Jakarta, Indonesia & [GenBank: EF186499] & [GenBank: EF186614] & R3 \\
\hline ABTC47999 & R. tanezumi & Jakarta, Indonesia & [GenBank: EF186500] & [GenBank: EF186615] & $\mathbf{R 3}$ \\
\hline ABTC48000 & R. tanezumi & Jakarta, Indonesia & [GenBank: EF186501] & [GenBank: EF186616] & $\mathbf{R 3}$ \\
\hline ABTC48004 & R. tanezumi & Northern Sulawesi, Indonesia & [GenBank: EF186511] & [GenBank: EF186626] & $\mathbf{R 3}$ \\
\hline ABTC48005 & R. tanezumi & Northern Sulawesi, Indonesia & [GenBank: EF186512] & [GenBank: EF186627] & $\mathbf{R 3}$ \\
\hline ABTC 8489 & R. flavipectus (3) & Hong Kong, China & [GenBank: EF186440] & [GenBank: EF186555] & $\mathrm{R} 2$ \\
\hline Chat2 & R. exulans & Chatham Islands, New Zealand & [GenBank: EF186426] & [GenBank: EF186541] & $\mathrm{R} 8$ \\
\hline $\mathrm{Cl} 6$ & R. exulans & Aitutaki, Cook Islands & [GenBank: EF186414] & [GenBank: EF186529] & $\mathrm{R} 8$ \\
\hline Fiji1 & R. exulans & Fiji & [GenBank: EF186417] & [GenBank: EF186532] & $\mathrm{R} 8$ \\
\hline Hawaii3 & R. exulans & Hawaii & [GenBank: EF186418] & [GenBank: EF186533] & $\mathrm{R} 8$ \\
\hline
\end{tabular}


Table 3: Sequences from previous studies included in the $m t$ dataset. (Continued)

\begin{tabular}{|c|c|c|c|c|c|}
\hline Hu38 & R. exulans & Huahine, Society Islands & [GenBank: EF186420] & [GenBank: EF186535] & R8 \\
\hline Kap6 & R. exulans & Kapiti Island, New Zealand & [GenBank: EF186425] & [GenBank: EF186540] & R8 \\
\hline Ra22 & R. exulans & Raiatea, Society Islands & [GenBank: EF186429] & [GenBank: EF186544] & R8 \\
\hline RNZAwa01 & R. exulans & Great Barrier Island, New Zealand & [GenBank: EF186424] & [GenBank: EF186539] & $\mathrm{R} 8$ \\
\hline Samoa 3 & R. exulans & Manua, Samoa & [GenBank: EF186430] & [GenBank: EF186545] & R8 \\
\hline Taku5 & R. exulans & Takutea, Cook Islands & [GenBank: EF186416] & [GenBank: EF186531] & R8 \\
\hline UaHuka4 & R. exulans & UaHuka, Marquesas Islands & [GenBank: EF186422] & [GenBank: EF186537] & R8 \\
\hline ABTC 8480 & R. exulans & Thailand & [GenBank: EF186434] & [GenBank: EF186549] & R8 \\
\hline ABTC 8553 & R. exulans & Thailand & [GenBank: EF186432] & [GenBank: EF186547] & R8 \\
\hline ABTC 8559 & R. exulans & Thailand & [GenBank: EF186433] & [GenBank: EF186548] & R8 \\
\hline ABTC43078 & R. exulans & Yuro, Papua New Guinea & [GenBank: EF186427] & [GenBank: EF186542] & $\mathrm{R} 8$ \\
\hline ABTC48011 & R. exulans & Cibodas Forest, Java, Indonesia & [GenBank: EF186421] & [GenBank: EF186536] & R8 \\
\hline ABTC48895 & R. exulans & Nagada Harbour, Papua New Guinea & [GenBank: EF186428] & [GenBank: EF186543] & $\mathrm{R} 8$ \\
\hline ABTC65753 & R. hoffmanni & Tangoa, Sulawesi, Indonesia & [GenBank: EF186443] & [GenBank: EF186558] & - \\
\hline ABTC65754 & R. hoffmanni & Tangoa, Sulawesi, Indonesia & [GenBank: EF186441] & [GenBank: EF186556] & - \\
\hline ABTC65809 & R. hoffmanni & Mt Nokilalaki, Sulawesi, Indonesia & [GenBank: EF186442] & [GenBank: EFF186557] & - \\
\hline Rargen_1266 & R. argentiventer** & Bangkok, Thailand & $\begin{array}{l}\text { O.Verneau, } \\
\text { unpublished }\end{array}$ & - & R6 \\
\hline Rsikki_866 & R. sikkimensis**(4) & Mocchan, Vietnam & $\begin{array}{l}\text { O.Verneau, } \\
\text { unpublished }\end{array}$ & - & R7 \\
\hline ABTC48025 & R.tiomanicus & Cibodas Forest, Java, Indonesia & [GenBank: EF186514] & [GenBank: EF186629] & R5 \\
\hline ABTC48026 & R.tiomanicus & Cibodas Forest, Java, Indonesia & [GenBank: EF186513] & [GenBank: EF186628] & R5 \\
\hline Rn Ra 15 & R. norvegicus & Raiatea, Society Islands & [GenBank: EF186462] & [GenBank: EF186577] & R9 \\
\hline Rn Hu 21 & R. norvegicus & Huahine, Society Islands & [GenBank: EF186461] & [GenBank: EF186576] & R9 \\
\hline
\end{tabular}

"Nominal species" stands for the identification given to the specimen by the curator or the collector ([25] and F. Catzeflis, pers. comm.). "Phylogenetic species" relies on the DNA-based species delimitation method (see also Figure 3).

(1) Rattus rattus diardi: Robins et al [25] reports that the specimens ABTC64906-64910 are identified by the South Australian Museum as the subspecies Rattus rattus diardi (not diardii) as listed by Ellerman [71] on the basis on R. r. diardiafter Jentink [72]. As already mentioned by Robins et al., [25], R. diardii (after Jentink 1880) is however considered as a synonym for R. tanezumi by Musser and Carleton [16] but there is no 1880 reference in their bibliography.

(2) R. kandianus is listed as a synonym of R. rattus [16], (3) R. flavipectus of R. tanezumi [16], (4) R. sikkimensis of R. andamanensis [16].

** indicates that specimens are no more available in the mammal tissue collection housed at the Institut des Sciences de l'Evolution de Montpellier [73].

Mismatches between nominal species and phylogenetic species are highlighted in bold.

To check if it provides adequate discrimination for rat species, the whole cytb sequences of the 122 specimens were reduced to the $85 \mathrm{bp}$ fragment following the groups evidenced by the DNA-based species delimitation method. Based on our sampling, rat species could be easily discriminated with this small sequence (except the two entities hereafter named Be2a and Be2b but see discussion) (see the 85 bp alignment in additional file 1). So, we decided to target this DNA barcode from the holotype of Leopoldamys neilli.

As we used a museum specimen, the difficulties associated with ancient DNA studies are relevant to this analy- sis. Hence, ancient DNA work was performed at the PALGENE national platform (CNRS, ENS Lyon, France) dedicated to ancient DNA analysis, following the standard procedures and using specific equipment and personal protections [58,59].

DNA was extracted from the holotype of Leopoldamys neilli following the protocol detailed by Rohland and Hofreiter [60]. Primer sets declined from Télétchéa et al., [56] were used for PCR attempts (Table 2). At least two independent PCR amplifications were performed in 25 $\mu \mathrm{L}$ reaction volumes containing 2.5 units of Perkin Elmer Gold Taq polymerase (Applied Biosystems), $1 \mathrm{mg} / \mathrm{mL}$ 
BSA (Roche, $20 \mathrm{mg} / \mathrm{mL}$ ), $2 \mathrm{mM} \mathrm{MgCl}, 250 \mu \mathrm{M}$ of each dNTP, $0.5 \mu \mathrm{M}$ of primers. For each independent PCR attempt, a range of dilutions was performed to find the best compromise between inhibitor's concentration and targeted DNA molecule concentration. DNA was amplified with a 5 min activation step at $95^{\circ} \mathrm{C}$ followed by 55 cycles of denaturation $\left(94^{\circ} \mathrm{C}, 30 \mathrm{~s}\right)$, annealing $\left(48^{\circ} \mathrm{C}, 30 \mathrm{~s}\right)$ and elongation $\left(72^{\circ} \mathrm{C}, 45 \mathrm{~s}\right)$. Amplification products were systematically cloned using Topo TA Cloning for sequencing kit (Invitrogen). 16 clones of independent amplifications were sequenced to determine the consensus sequence (Macrogen, Seoul, South Korea).

The CAOS software, a two step character-based DNA barcoding method [61] was then used to determine if the Leopoldamys neilli holotype consensus sequence could be assigned to one of the clusters recognized as a putative species by the method of Pons et al., [28]. First, a diagnostic rules generator, P-Gnome, was used to search DNA changes through the $85 \mathrm{bp}$ cytb matrix (122 sequences) and to establish diagnostic rule sets for each of the previously described entities (outputs of the DNA-based species delimitation method). Then, the P-Elf program was run to classify as a query the holotype sequence according to the rules generated by $\mathrm{P}-\mathrm{Gnome}$.

\section{Results}

\section{Sequence analyses and phylogenetic reconstructions}

Cytb, IRBP and COI sequences were generated for 122, 120 and 116 rat specimens respectively. All sequences were deposited in GenBank under the accession numbers HM217360 to HM217717 (Table 1). No significant difference in nucleotide composition among taxa was detected which indicated that no artificial grouping could occur due to a misleading compositional signal in the dataset. PhyML analyses were first carried out on each locus independently (data not shown). Each gene considered separately does not result in a robust Rattini phylogeny: mitochondrial markers help to resolve terminal nodes, while IRBP lends support to deepest ones. But, since the 3 genes yielded consistent, compatible topologies, sequences were concatenated and phylogenetic analyses were then carried out using the combined dataset.

Identical topologies were obtained with and without a RY-coding of the $3^{\text {rd }}$ codon position (data not shown). However, better resolution and stronger topological supports (Bp and pp) were reached without an RY recoding strategy. It seems that our dataset was not informative enough for a RY recoding strategy resulting in this case in an over-depletion of the phylogenetic signal.

$\mathrm{BI}$, partitioned and unpartitioned ML analyses (without $\mathrm{RY}$ recoding strategy) yielded the identical topology given in Figure 2. Most relationships among the Rattini tribe were well resolved (supports 61-100 for Bp, 0.82-1.00 for pp). Monophyletic groups corresponding to the Rattini divisions proposed by Musser and Carleton [16] are sustained with the highest values of Bp or pp. The Maxomys division clearly appears as the first division to diverge followed by the Dacnomys division, here represented by Leopoldamys and Niviventer genera, and the Rattus division. Berylmys appears with maximum support values as the earliest lineage to diverge among the Rattus division. A sister grouping is indicated between the genera Bandicota and Rattus, but this association is weakly supported. In fact, the monophyly of the Rattus genus received moderate pp (0.82) to weak Bp supports (61 for unpartitioned, 63 for partitioned ML analyses). To test the reliability of these findings, we considered an alternative hypothesis concerning the position of Bandicota within the Rattus division (i.e. Bandicota was placed inside the Rattus sp. cluster). SH-test failed to find significant differences between these hypotheses and the alternative branching orders of Bandicota inside the Rattus division could not be excluded ( $\mathrm{P}>0.05)$. Inside the Rattus sp. clade, the 3 Rattus species groups proposed by Musser and Carleton [16] could be distinguished. The $R$. exulans monotypic group ( $R e$, Figure 2 ) clustered with the $R$. rattus species group $(R r$, Figure 2) with high branch supports $(\mathrm{Bp}=94 /$ 96 for the unpartitioned/partitioned ML analyses; $\mathrm{pp}=1$ ) and the $R$. norvegicus species group ( $R n$, Figure 2$)$ is placed as sister taxa to the $R$. exulans species group $/ R$. rattus species group cluster.

At this point in the analysis, 23 lineages (labelled R1 to M2 in the Figure 2) are identified within our taxon sampling. As their specific status are still questioned, intrageneric relationships are problematic to describe and will not be discussed in this section.

\section{Species delimitation}

The existence of distinct phylogenetic lineages was corroborated by the analysis of the branching rate pattern. A lineage-through-time plot based on the Multidivtime ultrametric tree evidenced a sudden increase in branching rate towards the present, likely corresponding to the switch from interspecies to intraspecies branching events (see additional file 2). To fit the position of the switch, the method of Pons et al. [28] was applied to the time calibrated tree (Figure 3). The GMYC model was preferred over the null model of uniform branching rates $(\log \mathrm{L}=$ 700.133, compared to null model $\log \mathrm{L}=687.218 ; 2 \Delta \mathrm{L}=$ 25.83, $\mathrm{x}^{2}$ test, d.f. $\left.=3, \mathrm{p}<0.0001\right)$. The model fitted the switch in the branching pattern occurring at -0.07084 (i.e. $\mathrm{T}$ of the ML solution/it is worth reminding that the time separating the ingroup root from the present was arbitrarily assigned to 1), leading to an estimate of 24 putative species, 4 of which containing a single individual (labelled $\mathrm{R} 5, \mathrm{Be} 2 \mathrm{~b}, \mathrm{~N} 2$ and N3 respectively in Figure 3). Two Maxomys (M1 and M2), 4 Niviventer (N1 to N4), 3 Leopoldamys (L1 to L3), 2 Bandicota (B1 and B2), 3 Berylmys 
(Be1, Be2a, Be2b) and 10 Rattus species (R1 to R10) could be numbered as indicated in Figure 3. It is worth noting that the Berylmys lineage (labelled Be2 in Figure 2) actually seems to correspond to two putative species following Pons et al's approach (therefore labelled Be2a and $\mathrm{Be} 2 \mathrm{~b}$ in Figure 3). Confidence interval for the threshold ranged from -0.09439 to -0.04189 and the estimated number of species ranged from 22 to 32 (i.e. estimates falling within $2 \log$-likelihood units of the ML solution).

\section{Species identification}

\subsection{Within the Rattus genus}

The partitioned ML analysis of the $m t$ dataset including 64 new Rattus sequences (this study) plus 61 from previous studies [25] gave the highly resolved and robust tree represented in Figure 4. This has allowed us to name some clusters identified as putative species by the DNAbased species delimitation method. Because the monophyly of each cluster embracing the supplementary published sequences is supported with the highest Bp value, the level of confidence of these identifications could be considered as maximal if the voucher identification beforehand is correct.

Robins' sequences identified as Rattus rattus cluster with $100 \%$ Bp support with sequences assigned to $R$. rattus specimens in [36]. Specific identification of group R1 as Rattus rattus is thus convincingly confirmed. According to the $m t$ tree, none of our samples from Thailand, Cambodia or Lao PDR could be assigned to this species. Following the same approach, R2 seems to correspond to Rattus tanezumi, R5 to Rattus tiomanicus, R8 to Rattus exulans and R9 to Rattus norvegicus. Sequences provided by O. Verneau and F. Catzeflis allow us identifying R6 as $R$. argentiventer and $\mathrm{R} 7$ as $R$. andamanensis. As expected, since its distribution is restricted to Sulawesi, sequences of Rattus hoffmanni group with none of our specimens. $R$. hoffmanni whose phylogenetic affinities among the Rattus rattus group need to be elucidated [16] appears as the sister taxa to R. argentiventer with strong support (88 $\mathrm{Bp})$. The situation appears more complex for the species R3. This group corresponds to a mix of specimens identified as $R$. rattus diardi in [25], Rattus kandianus (considered as a synonym of $R$. rattus, [16]) in [25], R. tanezumi from Indonesia [25] and $R$. tanezumi, $R$. andamanensis or $R$. argentiventer according to the field names we assigned during our sampling. Consequently, no nominal species could be reliably assigned to R3.

According to morphological criteria and because its sistership with Rattus norvegicus [16] (see Table 4 in discussion), R10 could be convincingly assigned to Rattus nitidus.

\subsection{Ancient DNA analysis of a holotype specimen}

Sequences obtained from holotype specimen We successfully obtained 85 bp cytb sequences from the Leopol- damys neilli holotype. At least two independent PCR runs were performed, positive PCR products were cloned and consensus sequences were determined using clone sequences of independent PCR amplifications. Analysis of the differences observed between the clone sequences and consensus sequence shows that $75 \%$ of the degradation was due to deamination of cytosines, as expected from ancient DNA substrates [62,63].

\section{Holotype sequence authentication The consensus} sequence was identified as a rat cytochrome $b$ sequence using a BLAST program (no Leopoldamys neilli cytochrome $b$ sequence was available in databanks such as EMBL or GenBank before this study). This sequence is a genuine holotype sequence for the following reasons: (i) Rattini samples were never introduced in the ancient DNA facilities before the analysis of this specimen was performed; (ii) all the 16 clones analysed were identified as rat; (iii) the errors induced by DNA damage are perfectly consistent with the pattern generally observed for ancient DNA sequences (strong bias toward type 2 transitions caused by deamination of cytosine $[62,63]$ ); (iv) for each amplification, all three PCR blanks remained negative [58]; (v) independent PCRs were performed and furnished the same conclusions. All in all, these points satisfy criteria of authentication for the ancient DNA work [59].

Assignment of the holotype sequence to a cluster The genuine holotype sequence was deposited in GenBank under the accession number HM235947. It was assigned using the CAOS software to the monophyletic cluster corresponding to the Leopoldamys species, L2, in our tree (Figures 2 and 3). Consequently, this monophyletic cluster recognized as a putative species by the method of Pons et al. [28] could be without ambiguity named as Leopoldamys neilli.

\section{Discussion \\ 1. Phylogenetic relationships within the Rattini tribe 1.1. Division-level relationships}

Our phylogenetic analyses of Indochinese Rattini based on the combination of cytb, $\mathrm{COI}$ and the first exon of the IRBP genes is compatible with the revised taxonomy of Rattini divisions proposed by Musser and Carleton [16]. The Maxomys division, the Dacnomys division (here consisting of Leopoldamys and Niviventer as sister taxa) and the Rattus division (here including the genera Rattus, Bandicota and Berylmys) are sustained with the highest support values (Figure 2). These results are congruent with the Murinae phylogeny obtained by Lecompte et al. [17] based on the analysis of the combined cytb, IRBP and GHR genes. In this latter analysis, the 3 divisions are well supported and the Maxomys division is also the first to diverge followed by the Dacnomys one and the Rattus group sensu stricto of Verneau [64]. 


\subsection{Relationships among the Rattus division: is the genus Rattus paraphyletic?}

In our analyses, the position of Bandicota still remains uncertain. The monophyly of the genus Rattus is in reality weakly supported ( 0.82 for $\mathrm{pp}$ and $61 / 63$ for $\mathrm{Bp}$ ) and $\mathrm{SH}$-test failed to reject the hypothesis of a paraphyletic Rattus genus (i.e. Bandicota is placed within Rattus). Verneau and collaborators [64,37] attempted to determine the evolutionary relationships in Rattus sensu lato using LINE-1 (L1) amplification events. In their study [37], two LINE subfamilies were identified in the Bandicota and the other Rattus species except in Rattus fuscipes. Since L1 subfamily absence from a particular taxa reflects an ancestral state rather than a derived state [64], these findings excluded Rattus fuscipes from a Bandicota/Rattus clade and placed Bandicota inside the genus Rattus leading to its paraphyly. Our study is in agreement with the multi-locus phylogeny of Lecompte et al., [17] which shows Bandicota and the genus Diplothrix diverging together prior to the Rattus clade. In the Lecompte's study, the monophyly of the genus Rattus is highly supported (98 Bp, $1 \mathrm{pp}$ ) but, as in our study, no specimen of the Rattus fuscipes species group was included. To draw conclusions about paraphyly in Rattus genus, it would be judicious to complete the taxa sampling among the genus Rattus and to include representatives of each Rattus species group defined by Musser and Carleton [16] particularly representatives of the Rattus fuscipes species group. 1.3. Relationships within the genus Rattus

The genus Rattus, with a total of 66 species currently recognised [16] "is not only the single largest mammalian genus of all, but also arguably among the most complex and least understood" [65].

Within this genus, 7 species groups have been defined by Musser and Carleton [16], of which 3 inhabit the Indochinese region and are relevant to this study ( $R r, R e$ and $\mathrm{Rn}$ in Figures 2 and 3). The Rattus rattus species group as described by Musser and Carleton [16] comprises 21 species of which 5 may be found in Thailand, Cambodia and Lao PDR. In our phylogenetic analysis, this cluster appears unambiguously to be monophyletic (1.00 for pp; 93/97 for $\mathrm{Bp}$ ) and was placed undoubtedly as the sister group of the monotypic exulans species group ( $\mathrm{pp}=1.00$; $\mathrm{Bp}=94 / 96)$. This association was also found in recent molecular studies $[25,17]$ but encompassing fewer representatives of the Rattus rattus species group. According to Musser and Carleton [16], the R. norvegicus species group includes 3 species (Rattus norvegicus, $R$. nitidus and R.pyctoris) of which only 2 may occur in the Indochinese region (Rattus norvegicus and $R$. nitidus). This group appears in our study as the sister taxa to the "R. exulans species group/ $R$. rattus species group" cluster as found in [25] and [17].
Robins and colleagues [25] focusing on rats inhabiting islands in Southeast Asia, included in their sampling specimens from Australia (i.e. belonging to the Rattus fuscipes species group as defined by [16]) and from New Guinea and adjacent archipelagos (i.e. belonging to the Rattus leucopus group). Based on the analysis of nearly 2 $\mathrm{kb}$ of $m t \mathrm{DNA}$, they recovered 5 of the 7 groups proposed by Musser and Carleton [16]. Our study, even if focusing on a different region of South East Asia, is perfectly congruent with Robins' study, and both studies are compatible with the revised taxonomy of the Rattus genus recently proposed by Musser and Carleton [16]. The sixth group defined by the authors [16] corresponds to the xanthurus species group encompassing species native to Sulawesi and adjacent islands. According to preliminary phylogenetic analyses of cytb sequences cited in [16], this assemblage could be placed as the sister-group to the $R$. leucopus and $R$. fuscipes groups. The last group defined by Musser and Carleton [16] does not correspond to a natural cluster but was formed for practical reasons since it includes species whose phylogenetic affinities have to be clarified; some may need to be excised from Rattus.

\section{Toward a deep taxonomic revision of the Rattini tribe}

At a specific level, we realized that phylogenetic relationships were difficult to discuss. Species misidentifications are indeed plentiful and recurrent both in our sampling (see Table 1) and in the literature. Mt sequences from Robins et al. [25] or provided by O. Verneau and F. Catzeflis were included in our dataset but questions about the reliability of the identification of vouchers were rapidly raised. To cite a few examples, the Rattus tanezumi sample occurring in the tiomanicus cluster in [25] (see Figure 4) was proposed by the authors to represent a misidentification. Similarly, the $R$. rattus $c f$. moluccarius specimen in [64] and [37] was, according to Musser and Carleton [16], an example of $R$. nitidus whereas their specimen assigned to Niviventer niviventer was probably improperly identified since $N$. niviventer has never been described in the locality where the specimen was caught [64]. We observed that the situation was worse regarding the Niviventer genus. When including sequences available in the databanks (i.e. cytochrome $b$ sequences from [66]), numerous species appeared to be paraphyletic (data not shown). These results are presumably the consequence of species misidentifications and this explains why we decided to exclude these sequences from our analyses. All in all, these reports $([25,64]$ and this study) stressed the necessity of a sound taxonomic revision of the Rattini tribe. Consequently one must first determine valid species boundaries and then assign an appropriate name in accordance with the rules of the International Code of the Nomenclature. 


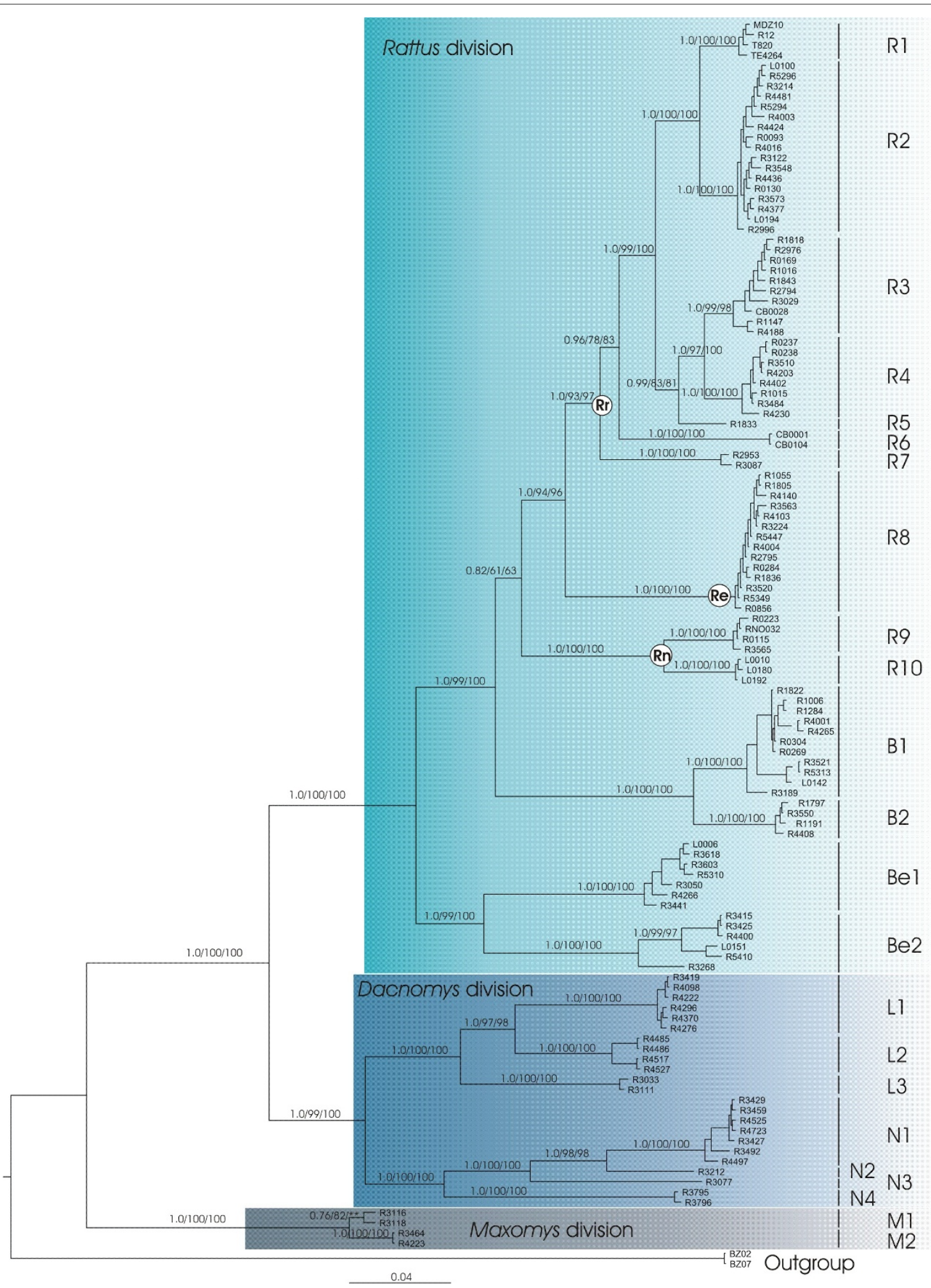

Figure 2 Phylogenetic tree depicting relationships of the Indochinese Rattini based on the analyses of the combined cytb, COI and IRBP genes and reconstructed following Bayesian method. Bl and ML analyses of the dataset gave an identical topology. Numbers above the branches reflect support obtained from the analysis of the dataset following 3 different reconstruction methods: BI/unpartitioned ML/partitioned ML. Support values are not shown for very short branches. The symbol "**" indicates that phylogenetic relationships are not supported by the partitioned ML analysis. Rr stands for Rattus rattus species group, Re for Rattus exulans species group, Rn for Rattus norvegicus species group, following Musser and Carleton's denominations [16]. At the right hand of the tree, lineages are labelled according to the genus to which they belong. 


\subsection{How many rat species in the Indochinese area we investigated?}

According to Musser and Carleton [16], 9 genera corresponding to the following 27 species of Rattini may occur in our sampling area (Figure 1): Hapalomys delacouri (see Background for justification of its inclusion into the Rattini tribe), Sundamys muelleri, Chiromyscus chiropus, 3 Maxomys species (rajah, surifer, whiteheadi), 6 Niviventer species (fulvescens, hinpoon, langbianis, tenaster, cremoriventer, confucianus), 3 Leopoldamys species (neilli, edwardsi, sabanus), 2 Bandicota species (indica and savilei), 2 Berylmys species (bowersi and berdmorei) and 8 Rattus species (andamanensis, argentiventer, exulans, tanezumi, losea, tiomanicus, norvegicus, nitidus). According to our phylogeny (Figure 2), 23 lineages exist within our sampling and 24 putative species were suggested by the method of Pons et al. [28]. Confidence interval for the estimated number of species ranged from 22 to 32 (i.e. estimates falling within 2 log-likelihood units of the ML solution). An inadequate population sampling is one of the potential limitations of the branch length method as identified by Pons et al. [28]. However, the GMYC model was preferred over the null model of uniform branching rates indicated that the intraspecific sampling effort is satisfactory in our dataset (failure to reject the null model over the GMYC model could be an incomplete sampling per species; [28]). Moreover, among the 24 estimated species, 4 species (labelled R5, Be2b, N2 and N3 respectively in Figure 3) contain a single individual. In accordance with Pons et al, it seems that the GMYC method correctly deals with the inclusion of some rare species represented by only one single individual [28].

The estimated number of species fit well with the number of species described in the literature for this area, although there are some exceptions, in particular within the Berylmys and the Rattus genera. Our study suggests 3 putative species of Berylmys in our sampling whereas only 2 are mentioned in the literature within the geographic area sampled (Berylmys bowersi and B. berdmorei) (see Table 4). This outcome was supported by all the solutions included in the $95 \%$ confidence interval of the estimate of the number of species (Figure 3). This finding may be an artefact of the species delimitation method which could have difficulty in dealing with high level of population differentiation and strong phylogeographic patterns. As acknowledged by Pons et al., [28], a limitation of this method is that populations with partial gene flow risk being recognized as separate entities. A marked phylogeographic structuring within Berylmys bowersi could explain the distinction of Be2a and Be $2 \mathrm{~b}$ as two putative species by the branch-length method. Be2b specimen came from the Kanchanaburi locality (Table 1, Figure 1), North to the Isthmus of Kra corresponding to the limit of the peninsular Thailand whereas the speci- mens of the Be2b group came from the Northern Thailand (Loei and Nan provinces, Figure 1) and Northern Lao PDR (Luang Prabang province, Figure 1). Populations of Berylmys bowersi in peninsular Thailand were reported to be geographically isolated and to differ in some ways from other populations [67]. Our findings are congruent with this report. Further investigations are needed to determine if $\mathrm{Be} 2 \mathrm{a}$ and $\mathrm{Be} 2 \mathrm{~b}$ are two phylogenetic lineages of a same species exhibiting a strong phylogeographical pattern or if they have two be considered as two closely related but separate species.

In a similar way, five species belonging to the Rattus rattus species group have been described in this area (i.e. $R$. andamanensis, argentiventer, tanezumi, losea, and tiomanicus). Marshall [33] reported also the presence of $R$. rattus in all provinces of Thailand and considered the roof rat as the most abundant mammal in the country. Interestingly, since 1998, no specimen among the 3,000 caught during our successive field surveys in rural or urban areas of Thailand, Lao PDR and Cambodia could be identified as a representative of $R$. rattus, according to morphological, cytological and molecular evidences. Our findings offer no support for the presence of $R$. rattus in the area and are in conflict with previous claims of $R$. rattus in the Indochinese region [33]. However, this inconsistancy is probably due to a difference in the usage of "Rattus rattus" in place of "Rattus tanezumi" rather than a problem of identification or occurrence.

Finally, our analysis corroborates the presence of an additional Rattus species (labelled R3 in Figure 3) already identified as the diardii clade in the mitochondrial phylogeny of Robins et al. [25]. R3 could be a cryptic species. This statement yet needs further investigation using independent data (morphology, nuclear genes). Then, if this hypothesis proved to be correct, the R3 species would have to be carefully named ( $R$. diardii is indeed considered at present as a synonym of $R$. tanezumi [16]). In agreement with our result, Aplin in his preliminary study of the cytb [65] observed that the taxonomy of the Rattus rattus species group might be rather thornier than suggested by previous studies mostly based on karyotypic or electrophoretic evidences. Indeed, his ongoing study reports two distinct phylogenetic clades in the Asian region. The first one would correspond to an endemic Southeast Asian taxon (recorded in Vietnam, Cambodia and Southern Laos) and might correspond to our R3 according to geographical evidence. Our study and Robins' work reveal that the distribution of this Southeast group spreads far into the South as it occurs in Thailand and in Sri Lanka and also in Malaysia, in Indonesia and Northern Sulawesi (Figures 4 and 5). The second clade proposed by Aplin [65] would be a northern and South Asian taxon (found in Japan, Hong Kong, northern Vietnam, northern Laos, and Bangladesh) and might corre- 


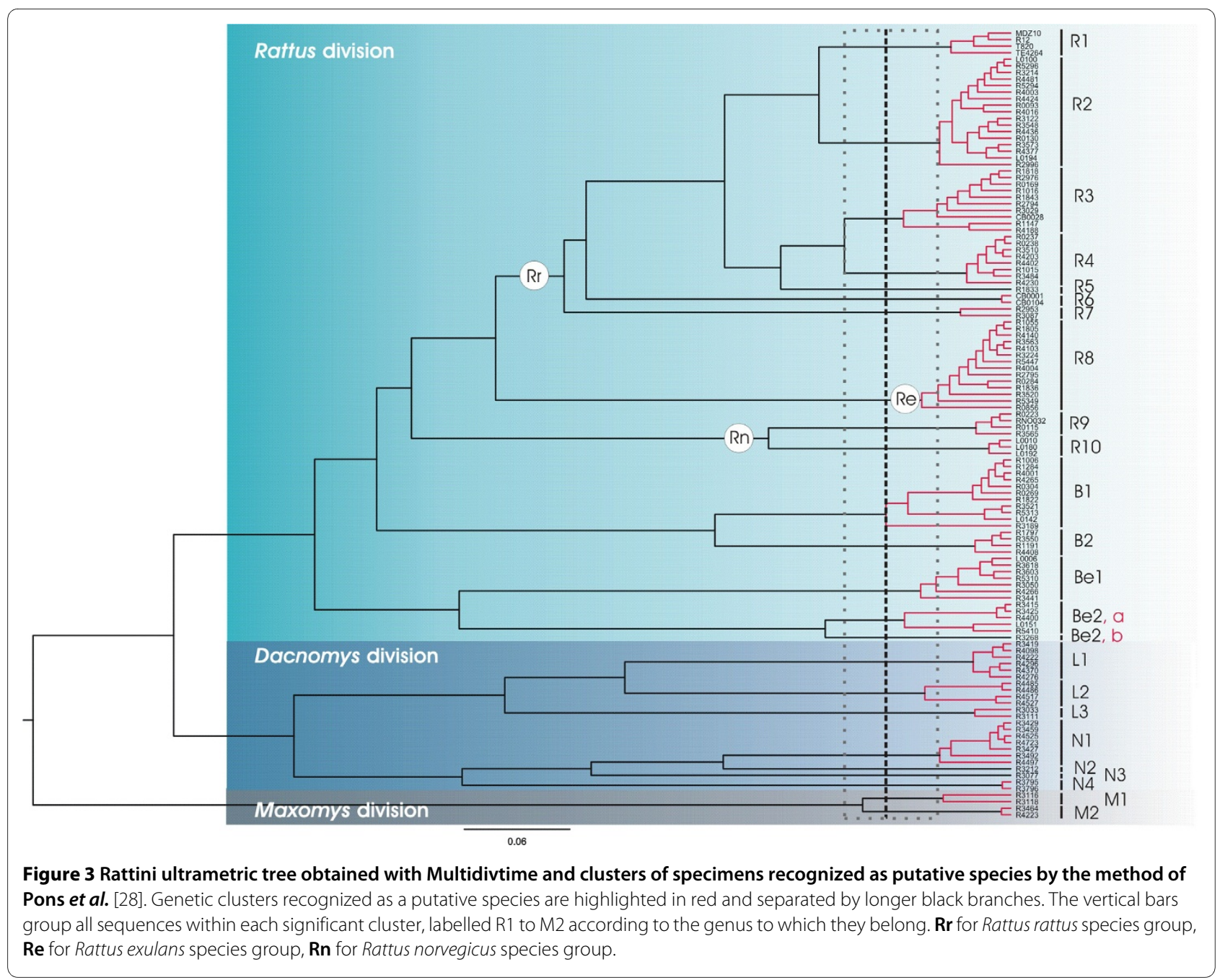

spond to R2 (here also found in Thailand and Indonesia, Figure 4, Table 3/see also Table 4 for species name). Indeed when including Robins' sequences, R2 includes specimens from Japan and Hong Kong (Figures 4 and 5). As mentioned by Aplin [65], the latter group (R2) is more closely related to Rattus rattus rather than the former group (R3). In our trees (Figures 2 and 4), R2 is clearly placed as the sister taxa of $R$. rattus (R1). Our study reinforces Aplin's assumption [65] that the two Asian clades (i.e. R2 and R3) are sympatric in some part of their distribution by increasing greatly the area where the two taxa co-occur in continental Southeast Asia. Both are found in Northern and Central Thailand (Phrae, Nakhon Pathom and Ratchaburi provinces; this study). Since some specimens of both taxa were trapped in exactly the same location and time, at least in Phrae, they probably also share similar habitats and are likely syntopic.

\subsection{How to give a name?}

By integrating phylogenetic, morphological and geographical evidence, we proposed to attribute the names summarized in Table 4 to the 24 species highlighted herein. Our propositions are not definitive but are revisable ones. Indeed, once species boundaries are delimitated, assigning the appropriate name to each species is not an easy task particularly for the Rattini species whose taxonomy is complicated by a large number of synonym names. Even for a rodent specialist, morphological characters are sometimes misleading (see aforementioned misidentification examples) and intraspecific morphological polymorphism makes the problem more difficult. To alleviate this last difficulty, morphological studies have to consider a large number of specimens, a process that may be difficult and time-consuming to perform.

These inconveniences highlighted the great interest in obtaining molecular data from a holotype. Indeed, the holotype is by definition the element to which the name of a taxon is permanently attached. Consequently, including holotype specimens in molecular phylogenies would be very suitable to name each cluster recognized as a valid species providing that a rigorous and sound taxonomy is already set up. Indeed, holotype specimens may correspond to problematic taxa (e.g. problems of synon- 


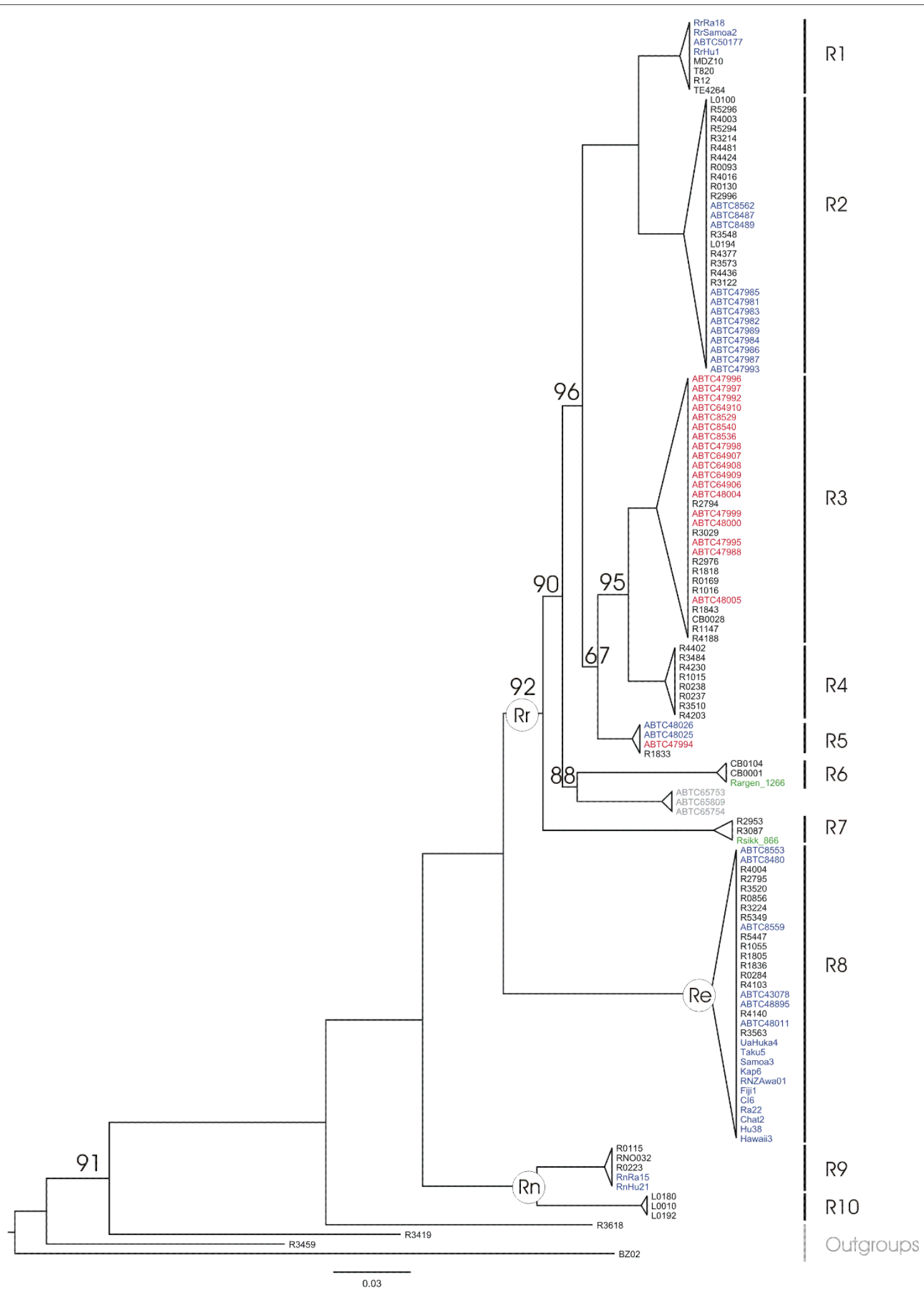

Figure $4 \mathrm{ML}$ tree depicting relationships within the Rattus division on the basis of $m \boldsymbol{t}$ dataset and estimated using partitioned $\mathrm{ML}$ analysis Bp values are shown above branches. Bp values equal to 100\% are not indicated. Robins' sequences are highlighted in blue when nominal and phylogenetic species are congruent, in red on the contrary (see also Table 3). Rattus hoffmanni sequences are indicated in grey; sequences provided by Verneau and Catzeflis in green. $\mathbf{R r}$ for Rattus rattus species group, Re for Rattus exulans species group, $\mathbf{R n}$ for Rattus norvegicus species group. At the right hand of the tree, cluster denomination is the same as in the Figure 3. 
Table 4: Species names proposed for each species recognized as putative ones by the method of Pons et al., .

\begin{tabular}{|c|c|c|c|}
\hline $\begin{array}{l}\text { Phylogenetic } \\
\text { species }\end{array}$ & $\begin{array}{l}\text { Species name } \\
\text { proposed }\end{array}$ & Phylogenetic evidences & $\begin{array}{l}\text { Morphological, geographical and } \\
\text { ecological evidences }\end{array}$ \\
\hline R1 & Rattus rattus & $\begin{array}{l}\text { R1 specimens identified in [36] cluster } \\
\text { unambiguously with } R \text {. rattus specimens } \\
\text { identified by Robins et al. [25] (see Figure 4). It } \\
\text { is worth noting that, during this study, this } \\
\text { species was never sampled in the fields in } \\
\text { Thailand, Laos and Cambodia. }\end{array}$ & \\
\hline $\mathbf{R 2}$ & Rattus tanezumi & $\begin{array}{l}\text { R2 specimens cluster unambiguously with } R \text {. } \\
\text { tanezumi specimens identified in [25] (see } \\
\text { Figure 4). }\end{array}$ & $\begin{array}{l}\text { Medium-sized rat; fur light brown to } \\
\text { reddish brown above, white below; dark } \\
\text { tail, equal or longer than head and body } \\
\text { length; caught in a large range of habitats, } \\
\text { from houses, gardens, crops and rice fields } \\
\text { to the edge of secondary forests. }\end{array}$ \\
\hline R3 & $\begin{array}{l}\text { Rattus sp.(to be } \\
\text { named) }\end{array}$ & $\begin{array}{l}\text { R3 includes specimens identified as Rattus } \\
\text { diardii in the study of Robins et al., [25] and rats } \\
\text { referred to Malaysian house rat (i.e. Rattus } \\
\text { diardii) by local populations in Indonesia } \\
\text { (Andru, J., pers. comm.). Today, Rattus diardii } \\
\text { has been placed as a synonym of Rattus } \\
\text { tanezumi according to morphological criteria. }\end{array}$ & $\begin{array}{l}\text { Urban rat or rat living near human } \\
\text { habitations. Misidentified by us as Rattus } \\
\text { tanezumi, } R \text { argentiventer and } R \text {. } \\
\text { andamanensis in the Rattus rattus species } \\
\text { group. }\end{array}$ \\
\hline R4 & $\begin{array}{l}\text { Rattus losea or } \\
\text { "losea-like" }\end{array}$ & & $\begin{array}{l}\text { Medium-sized rat; shaggy fur brownish } \\
\text { grey above, white to geyish below; dark } \\
\text { tail, shorter than head and body length; } \\
\text { caught mostly in rice fields and sometimes } \\
\text { in dry agricultural fields. According to } \\
\text { Aplin [35] two distinct forms of } R \text {. losea } \\
\text { may exist. True } R \text {. losea (described from } \\
\text { Taiwan) would be distributed from } \\
\text { Southern China to central Vietnam. The } \\
\text { second form "losea-like" would inhabit the } \\
\text { Mekong Delta region from Southern } \\
\text { Vietnam, Cambodia, Thailand, to the North } \\
\text { of Vientiane Province in Laos. Since our } \\
\text { analyses did not include samples from the } \\
\text { two putative groups, it was not possible to } \\
\text { determine if they are genetically distinct. } \\
\text { Until this taxonomic issue is resolved, we } \\
\text { prefer to name R4 "losea-like". }\end{array}$ \\
\hline R5 & $\begin{array}{l}\text { Rattus } \\
\text { tiomanicus }\end{array}$ & $\begin{array}{l}\text { R5 specimens cluster unambiguously with } \\
\text { R. tiomanicus specimens identified in [25] (see } \\
\text { Figure 4). }\end{array}$ & $\begin{array}{l}\text { Medium-sized rat; fur brown above, white } \\
\text { below; dark tail, slightly longer than head } \\
\text { and body length; arboreal; caught in palm } \\
\text { plantations. Morphologically very similar } \\
\text { to Rattus tanezumi but with shorter guard } \\
\text { hairs. }\end{array}$ \\
\hline R6 & $\begin{array}{l}\text { Rattus } \\
\text { argentiventer }\end{array}$ & $\begin{array}{l}\text { R6 sequences cluster unambiguously with } \\
\text { R. argentiventer sequences provided by } \mathrm{O} \text {. } \\
\text { Verneau and F. Catzeflis (see Figure 4)/ } \\
\text { identification of Verneau's specimen } \\
\text { confirmed by G. Musser [64]. }\end{array}$ & $\begin{array}{l}\text { Medium-sized rat; fur yellowish brown } \\
\text { above, grey-white below, with developed } \\
\text { guard hair on the back, distinct orange } \\
\text { fringe of fur just forward of the ear; dark } \\
\text { tail, shorter than head and body length; } \\
\text { caught in rice fields and plantations. }\end{array}$ \\
\hline
\end{tabular}


Table 4: Species names proposed for each species recognized as putative ones by the method of Pons et al., . (Continued)

\begin{tabular}{|c|c|c|c|}
\hline R7 & $\begin{array}{l}\text { Rattus } \\
\text { andamanensis }\end{array}$ & $\begin{array}{l}\text { R7 sequences cluster unambiguously with } \\
\text { R. sikkimensis sequences provided by O. } \\
\text { Verneau and F. Catzeflis (see Figure 4). }\end{array}$ & $\begin{array}{l}\text { Medium-sized rat; fur orange brown } \\
\text { above, white-creamy below, with very } \\
\text { elongated guard hairs; dark tail, longer } \\
\text { than head and body length; caught in } \\
\text { evergreen forests. }\end{array}$ \\
\hline $\mathbf{R 8}$ & Rattus exulans & $\begin{array}{l}\text { R8 specimens cluster unambiguously with } \\
\text { R. exulans specimens identified in [25] (see } \\
\text { Figure 4). }\end{array}$ & $\begin{array}{l}\text { Small-sized rat; fur grey-brown above, pale } \\
\text { grey below; dark tail, longer than head and } \\
\text { body length; domestic species found in } \\
\text { houses. }\end{array}$ \\
\hline R9 & $\begin{array}{l}\text { Rattus } \\
\text { norvegicus }\end{array}$ & $\begin{array}{l}\text { R9 specimens cluster unambiguously with } \\
\text { R. norvegicus specimens identified in [25] (see } \\
\text { Figure 4). }\end{array}$ & $\begin{array}{l}\text { Large-sized rat; fur dark-grey above, pale } \\
\text { grey below; tail shorter than head and } \\
\text { body length, dark above and paler } \\
\text { beneath but not clearly separated; occurs } \\
\text { in major ports and neighbouring cities. }\end{array}$ \\
\hline R10 & Rattus nitidus & $\begin{array}{l}\text { Sister relationship with Rattus norvegicus } \\
\text { evidenced by molecular data (see Figure } 2 \text { ). }\end{array}$ & $\begin{array}{l}\text { Medium-size rat with a soft woolly fur, } \\
\text { dorsally brown and grey-based cream on } \\
\text { belly. Pearly white feet. A nitidus/ } \\
\text { norvegicus sistership was proposed by } \\
\text { morphologists. According to Musser and } \\
\text { Carleton [11], both have "dense and soft } \\
\text { fur, six pairs of teats, and an upper M1 in } \\
\text { which the anterolabial cusp on the } \\
\text { anterior lamina is missing or undetectable } \\
\text { due to its coalesence with the adjacent } \\
\text { central cusp". }\end{array}$ \\
\hline B1 & $\begin{array}{l}\text { Bandicota } \\
\text { indica }\end{array}$ & $\begin{array}{l}\text { Only two Bandicota species have been } \\
\text { described in the Indochinese region. Usually, } \\
\text { B. indica specimens are unambiguously larger } \\
\text { than } B \text {. savilei. Adult } B \text {. savilei and juvenile or } \\
\text { immature } B \text {. indica may be confounded. A } \\
\text { molecular test based on PCR amplifications } \\
\text { with specific primers allowing discriminating } \\
\text { between the } 2 \text { species (Chaval et al., in prep.) } \\
\text { was used in such cases (data not shown). }\end{array}$ & $\begin{array}{l}\text { Large-sized rat; fur dark above, grey } \\
\text { below; tail shorter than head and body; } \\
\text { aggressive and stocky; inhabits } \\
\text { agricultural fields. The ratio of pes length } \\
\text { to head+body length is used to } \\
\text { distinguish B.indica from B.savilei [74]. }\end{array}$ \\
\hline B2 & $\begin{array}{l}\text { Bandicota } \\
\text { savilei }\end{array}$ & & $\begin{array}{l}\text { Medium-sized rat; fur dark above, grey } \\
\text { below; tail shorter than head and body; } \\
\text { inhabits dry lands, grasslands, clearings in } \\
\text { forest. }\end{array}$ \\
\hline Be1 & $\begin{array}{l}\text { Berylmys } \\
\text { berdmorei }\end{array}$ & & $\begin{array}{l}\text { Medium-sized rat; fur grey above, white } \\
\text { below; tail shorter than head and body; } \\
\text { inhabits secondary forests and fields close } \\
\text { to forests. }\end{array}$ \\
\hline Be2a & $\begin{array}{l}\text { Berylmys } \\
\text { bowersi }\end{array}$ & & $\begin{array}{l}\text { Large-sized rat; fur grey above, white } \\
\text { below; tail slightly longer than head and } \\
\text { body; inhabits secondary forests and fields } \\
\text { close to forests. }\end{array}$ \\
\hline
\end{tabular}


Table 4: Species names proposed for each species recognized as putative ones by the method of Pons et al., . (Continued)

Be2b Berylmys sp.
Berylmys mackensiei has been described in the Indochinese region by Marshall [33]. However the skull of $B$. mackenziei he studied was identified by Musser and Newcomb [75] as B. bowersi. Populations of Berylmys bowersi in peninsular Thailand were reported to be geographically isolated and to differ in some ways from those elsewhere (here speculated as to be Be2,a) [67]. Be2b specimen came from the Kanchanaburi locality, North to the isthmus of Kra and could consequently belong to this former particular population. Because of the lack of additional information about this specimen, no species name could be convincingly assigned to $\mathrm{Be} 2 \mathrm{~b}$.

\begin{tabular}{ll}
\hline $\mathrm{L} 1$ & $\begin{array}{l}\text { Leopoldamys } \\
\text { edwardsi }\end{array}$
\end{tabular}

\begin{tabular}{ll}
\hline L2 & $\begin{array}{l}\text { Leopoldamys } \\
\text { neilli }\end{array}$
\end{tabular}

Genuine sequence obtained from the holotype specimen of $L$. neilli was assigned to L2 without ambiguities.
Large-sized rat; fur red-brown above, white-cream below; very long tail, longer than head and body; inhabits secondary forests.
Large-sized rat (but the smallest Leopoldamys species); fur greyish -brown above, white-cream below; tail longer than head and body. Until now, the species has been recorded from a few locations in limestone areas of northern and South western Thailand, North of the peninsular region [76]. Our specimens were also trapped on tower karst in northern and northeastern Thailand (Phrae and Loei provinces).

L3 Leopoldamys

Large-sized rat; fur red-brown above, white-cream below; very long tail, longer than head and body; inhabits secondary forests. Caught in secondary forests. Often misidentified as Leopoldamys edwardsi. The two species of Leopoldamys sabanus and Leopoldamys edwardsi are indeed morphologically very similar. The species name we proposed for $L 3$ is based on geographical evidences from Marshall (1977). Based on his work, the only Leopoldamys species that has been described in Kanchanaburi province is Leopoldamys sabanus. The L3 specimens were caught in this province.
N1

\section{Niviventer}

fulvescens
Medium-sized rat; spiny fur red-brown above, white-cream below; tail longer than head and body, sharply bicoloured from base to tip; absence of terminal pencil and smallest length of bulla make us exclude Niviventer confucianus as species name. 
Table 4: Species names proposed for each species recognized as putative ones by the method of Pons et al., . (Continued)

$\begin{array}{ll}\text { N2 Niviventer sp. 1 } & \text { Marshall [67], Musser [77] and Corbet [34] } \\ & \text { documented the occurrence of Niviventer } \\ & \text { bukit in Kanchanaburi, where } \\ & \text { representatives of N2 and N3 species were } \\ & \text { caught. One of the two could be N. bukit. } \\ & \text { However, bukit is today considered as } \\ & \text { conspecific with Niviventer fulvescens [16]. } \\ & \text { Consequently, we prefer to refrain from } \\ & \text { giving a species name to these } 2 \text { species. }\end{array}$

N3

N4

Niviventer sp. 2

Niviventer
langbianis or
Chiromyscus
chiropus

N4 is placed at the base of the Niviventer group. It could thus belong to the genus Niviventer or to a sister genus to Niviventer. According to Musser and Carleton [16], Chiromyscus is presumed to be one of the closest phylogenetic relatives of Niviventer. Based on morphological criteria, this specimen could be a Chiromyscus chiropus representative. However, Chiromyscus chiropus is morphologically very closed to $N$. langbianis. Thus, $\mathrm{N} 4$ could be one of these two species. At the end of this work, we have just received $N$. langbianis samples from the AMCC. Our preliminary work based on mitochondrial DNA suggests that N4 may be $N$. langbianis rather than C. chiropus.
Identified in the field as Nu-deng because of its reddish fur (in Lao, "red rat"). Further considerations of pictures of one of the two specimens included in this study show that legs, feet and head are buffy orange as described by Musser [77] regarding Chiromyscus chiropus. However, the wide dark brown rings around the eyes are not visible and the tail is not bicoloured as expected for Chiromyscus. Chiromyscus is morphologically very close to Niviventer langbianis [77] and easily confused with it. Other criteria to discriminate between the two species such as the presence of a nail on each hallux instead of a claw for Chiromyscus are not obvious on our pictures. Morphological identification is thus questionable. However, molecular data are tipping the balance for $N$. langbianis assignation.
M1

Maxomys sp.
Identified by us as Maxomys surifer in the field. Could be assigned to Maxomys rajah but this species has never been reported in this area. This result could be to a bias of the branching-length method that could have some difficulties to deal with strong phylogeographic pattern. The phylogeography of Maxomys surifer was investigated using $m t$ DNA but focusing on the large Sunda shelf area [78]. A structuration between the North-eastern Vietnam and the Southern Vietnam seems to exist but this finding is based on only four sampled (for which sequences are not available in databanks). As a greater sampling and more additional data are needed to assess the phylogeographic pattern of this species, we prefer to refrain from giving a species name to this cluster.

M2 $\begin{aligned} & \text { Maxomys } \\ & \text { surifer. }\end{aligned}$

surifer.
Medium-sized rat; spiny fur red-brown above, white-cream below; tail slightly longer but nearly equal to head and body length, sharply bicoloured with a white tip. This is the only Maxomys species described in this area

The congruence between geographical, morphological and phylogenetic data allows us proposing species names. Waiting for a complete taxonomic revision of the Rattini tribe, these propositions are not definitive but are revisable ones. 


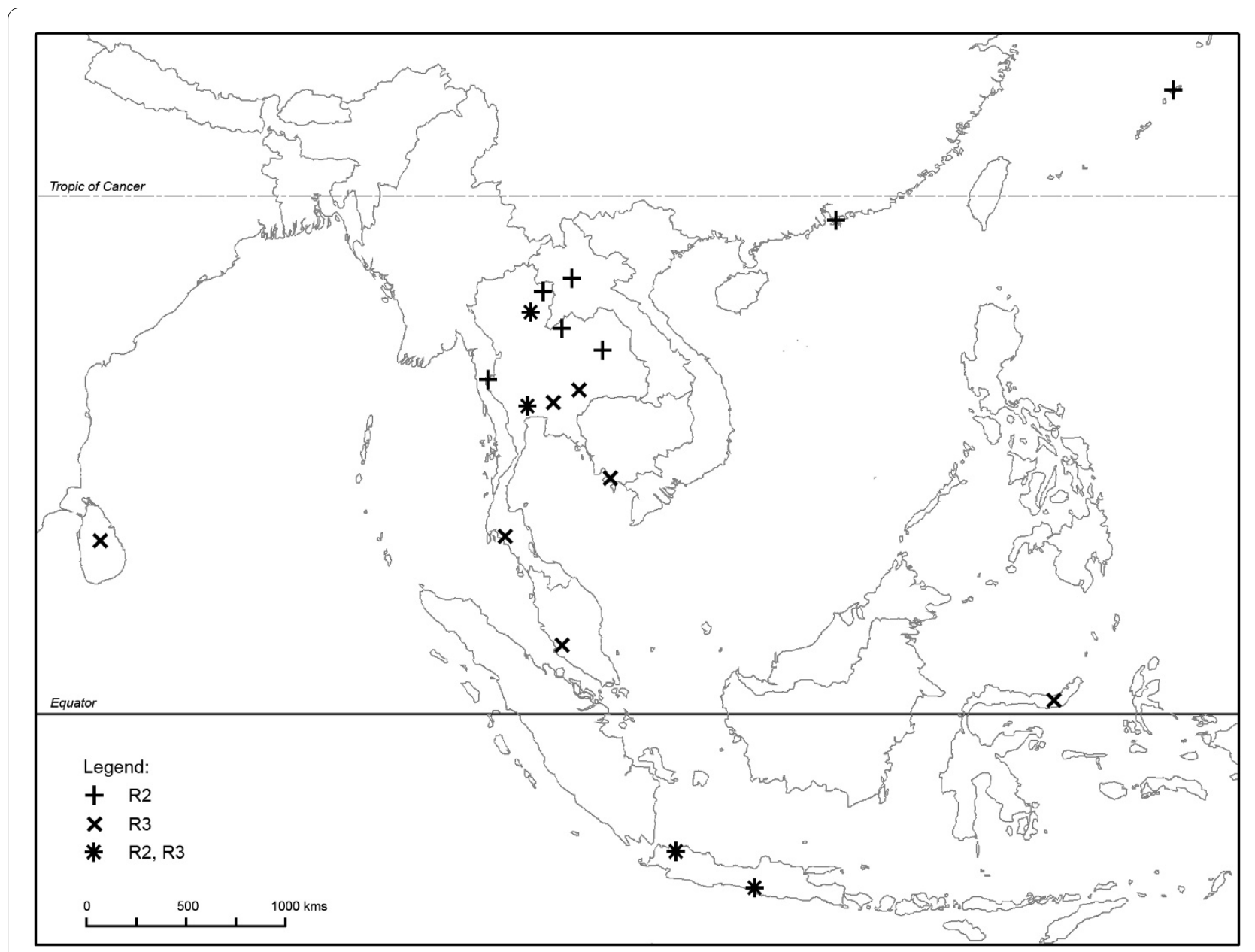

Figure 5 Map of the distribution of the two Asian species of the Rattus rattus species group, according to the samples identified as belonging to R2 and R3 in our study. (Figures 3 and 4 ).

ymy not yet revealed), and the use of type specimens could be misleading in such context. Including holotype specimens in molecular phylogenies is however totally infeasible for the two following reasons. Firstly, holotype specimens are unique and are difficult to obtain for genetic research purposes. Sampling authorisations are very scarce and destructive sampling is generally not possible. To achieve our study, no more than 24 holotypes would be damaged if our assumptions are correct. Faced with the understandable reluctance of museum curators, non-destructive extraction procedure [68] would be an elegant suggestion. Secondly, ancient materials contain tiny amounts of poorly preserved and highly fragmented DNA. As required for this study, getting $3 \mathrm{~kb}$ corresponding to 3 different genes (including one nuclear one) for more than 24 holotype specimens, and following the ancient DNA guidelines would be too expensive and much too time-consuming. To circumvent this problem it is fortunately possible to target small DNA fragments as barcodes. Our study proved that this strategy is a power- ful one. Following all the ancient DNA requirements, we succeeded in amplifying a genuine small cytb fragment from the Leopoldamys neilli holotype. This barcode was used to assign a name without ambiguity to one of the clusters (i.e. L2) recognized as a valid species in our analyses. Even if more holotype specimens have to be investigated to achieve a steady revision of the Rattini tribe, our work illustrates the huge opportunities ancient DNA analysis may offer to taxonomists.

\section{Conclusions}

This study represents the first step of a long-term project aiming at a deep taxonomic revision of the Rattini. Putative species delimitations have been determined here without prior assumptions and we propose a suitable methodology using molecular data from holotypes to assign the right name to each delineated species. Ancient DNA analysis of holotypes should be considered by taxonomists as a promising tool opening up new realms of possibilities (e.g. testing synonymy of names of unclear 
taxonomies such as the synonymy of $R$. tanezumi and $R$. diardii; see Table 4). Although DNA data alone are not a panacea for species description and delimitation, we are confident that future investigations combined with other types of information will clarify the taxonomy of this confusing group. Indeed, integrative approaches merging independent data such as morphology, karyology, mitochondrial and nuclear markers are the only means to understand the diversification among, and interactions between, evolutionary lineages. Our molecular study revealed that at least 7 putative different species, including a cryptic one (R3), could exist among the Rattus rattus species group (among which six were sampled within the area we investigated). As each of these species is expected to have specific ecological traits and to carry its own set of diseases, the recognition of cryptic species within Rattini could have serious implications for human health in Southeast Asia. However, this result has to be carefully considered. Indeed, it is worth noticing that the terminal nodes of our multilocus phylogeny are mostly supported by mitochondrial data (cytb and COI genes) while the deepest nodes are sustained by nuclear data (IRPB). Other kinds of markers have thus to be checked for congruence. Such clarifications for the Rattini tribe are today urgently required to achieve meaningful epidemiological research in South East Asia.

\section{List of Abbreviations}

bp: base pairs; kb: kilo base pairs.

\section{Additional material}

Additional file $\mathbf{1}$ Rat $\mathbf{8 5}$ pb cytb alignment. The whole cytb sequences obtained from the 122 specimens selected in this study were reduced to the 85 bp DNA marker already used to discriminate closely related species from degraded DNA [56,57]. Small sequences were sorted following the results of the DNA-based species delimitation method. Dots indicate identical positions as those of the reference sequence of Rattus rattus R12. Sites allowing discrimination between species are those shared by all the specimens of a same entitie but different for all the specimens of another one. Each rat species could be distinguished from each other based on this fragment except the two Berylmys species Be2a and Be2b (but see discussion). We tried to maximize the geographic diversity of the specimens, however, our sampling was achieved without prior expectation and some entities determined by the DNA-based species delimitation method encompass few specimens coming from the same locality (e.g. R5, R6, R7, Be2b, L3, etc.). In this case, intra-polymorphism is not taken into account and substitutions allowing discriminatation between species are thus overestimated. However, closely related rat species (such as R1 and R2 or R3 and R4, see phylogeny in Figure 2) could be easily discriminated. We thus considered that this fragment is reliable for an adequate discrimination for rat species.

Additional file $\mathbf{2}$ Lineage-through-time plot based on the Multidivtime ultrametric tree. The sudden increase in branching rate, indicated by a red line, corresponds to the shift from interspecific to intraspecific lineage branching.

\section{Authors' contributions}

Conceived and designed the experiments: JM, JFC, MP. Performed the experiments: MP, YC, VH, SW. Analyzed the data: MP. Wrote the paper: MP, YC. Senior epidemiologists and supervisors responsible for all scientific output of the program: SM, JM, JPH. All authors read and approved the final manuscript.

\section{Acknowledgements}

Firstly, we would like to thank the two anonymous reviewers for their comments that helped us to greatly improve the manuscript. We thank K. Blasdell for English corrections. We are particularly grateful to the people who have made this work possible in the field: S. Jittapalapong from the Faculty of Veterinary Medicine, W. Rerkamnuaychoke from the Faculty of Veterinary Technology at Kasetsart University in Thailand, B. Douangboupha from the National Agricultural and Forestry Research Institute in Lao PDR and P. Buchy from the Pasteur Institute in Cambodia. We also warmly thank all the people that worked hard with us in the field to collect samples used in this study, and especially K. Chaisiri and K. Satchasataporn. Thanks to C. Tollenaere and F. Catzeflis who provided us rat sequences or samples. We would like to acknowledge the Ambrose Monell Cryo Collection (AMCC) at the American Museum of Natural History, New York, for their support in our research. We are indebted to all the people of the ancient DNA platform PALGENE (directed by C. Hänni) and more particularly to B. Gillet. Thanks to L. Missa and S. Sutjarit for help in the lab and to C. Corbisier who started this work during her master study. Thanks to A. Cruaud, JY. Rasplus, E. Jousselin and G. Kergoat for helpful discussions, to G. Dobigny for constant support. We express gratitude to PH. Fabre who offered us judicious advice to use the Multidivtime software and help us to obtain the ultrametric tree needed in this study. Many thanks from Asia to T. Barraclough for help for the R code.

This work was supported by the French GIPANR, Programme Santé Environnement - Santé Travail (Program 00121 05), by the PHC Franco-Thai Cooperation in Higher Education and Research (Program No.16601PK). This study is part of the "CERoPath project" (Community ecology of rodents and their pathogens in South-East Asia: effects of biodiversity changes and implications in health ecology/ANR 07 BDIV 012) funded by the French National Agency for Research.

\section{Author Details}

IINRA, UMR CBGP (INRA/IRD/Cirad/Montpellier SupAgro), Campus International de Baillarguet, CS 30016, 34988 Montferrier-sur-Lez cedex, France , 2 Cemagref, Territories, Environment, Remote Sensing and Spatial Information Joint Research Unit (UMRTETIS), Maison de la Télédétection, 500 rue J-F Breton, 34093 Montpellier Cedex 5, France, ${ }^{3}$ Institut de Recherche pour le Développement (IRD), Research Unit UR178, Center for Vectors and Vectorborne Diseases (CVVD), Faculty of Sciences, Mahidol University, Bangkok 10400, Thailand, ${ }^{4}$ Thailand Institute of Scientific and Technological Research, Bangkok, Thailand, ${ }^{5}$ Muséum National d'Histoire Naturelle, Origine, Structure et Evolution de la Biodiversité, Paris, France, 6 Institut des Sciences de l'Evolution, CNRS-UM2, Université Montpellier 2, 34095 Montpellier, France, 7UR AGIRs, CIRAD, Campus International de Baillarguet 34398 Montpellier, France and \&Laboratoire de génétique des microorganismes, Institut de Botanique, Université de Liège, 4000 Liège (Sart Tilman), Belgique

Received: 21 July 2009 Accepted: 18 June 2010

Published: 18 June 2010

\section{References}

1. Morand S, Krasnov BR, Poulin R: Micromammals and macroparasites: from evolutionary ecology to management Tokyo: Springer-Verlag; 2006.

2. Herbreteau V, Henttonen H, Yoshimatsu K, Gonzalez JP, Suputtamongkol, Hugot JP: Hantavirus coevolution with their rodent hosts. In Encyclopedia of infectious diseases. Modern methodologies 1st edition. Edited by: Tibayrenc, M. Wiley J \& Sons Inc; 2007:243-264.

3. Henttonen H, Buchy P, Suputtamongkol Y, Jittapalapong S, Herbreteau V, LaakkonenJ, Chaval Y, Galan M, Dobigny G, Charbonnel N, Michaux J, Cosson JF, Morand S, Hugot JP: Recent discoveries of new hantaviruses widen their range and question their origins. Ann N Y Acad Sci 2008, 1149:84-89

4. Jittapalapong S, Herbreteau V, Hugot JP, Arreesrisom P Karnchanabanthoeng A, Rerkamnuaychoke W, Morand S: Relationship of parasites and pathogens diversity to rodents in Thailand. Kasetsart $J$ 2009, 43:106-117.

5. Meerburg B, Singleton G, Kijlstra A: Rodent-borne diseases and their risks for public health. Critical Reviews in Microbiology 2009, 35:221-270

6. Ostfeld R, Keesing F: Biodiversity and disease risk: the case of Lyme disease. Conserv Biol 2000, 14:722-728. 
7. Suzán G, Marcé E, Giermakowski JT, Mills JN, Ceballos G, Ostfeld RS, Armien B, Pascale JM, Yates TL: Experimental evidence for reduced rodent diversity causing increased hantavirus prevalence. PLOS ONE 2009, 4:e5461.

8. Chivian E: Biodiversity: its importance to human health Boston, Massuschets Harvard Medical School; 2003.

9. Morand S, Krasnov B, Poulin R: Global change, biodiversity and the future of mammals-parasite interactions. In Micro-mammals and macroparasites: from evolutionary ecology to management Edited by: Morand S, Krasnov BR, Poulin R. Tokyo: Springer-Verlag; 2006:617-635.

10. de la Rocque S, Morand S, Hendrix G: Climate change and pathogens. Rev Sci Tech Office International des Epizooties 2008, 27:.

11. Wilson D, Reeder D: Mammal Species of the World. A Taxonomic and Geographic Reference 3rd edition. Edited by: Johns Baltimore. Maryland Hopkins University Press; 2005.

12. Jenkins PD, Kilpatrick W, Robinson M, Timmins R: Morphological and molecular investigations of a new family, genus and species of rodent (Mammalia: Rodentia: Hystricognatha) from Lao PDR. System Biodivers 2005, 2:419-454.

13. Musser G, Smith A, Robinson MF, Lunde D: Description of a new genus and species of rodent (Murinae, Muridae, Rodentia) from the Khammouan limestone national biodiversity conservation area in Lao PDR. Am Mus Novit 2005, 3497:1-31

14. Helgen KM: A new species of murid rodent (genus Mayermys) from South-eastern New Guinea. Mamm Biol 2005, 70:61-67.

15. Musser G, Lunde D, Truong Son N: Description of a new genus and species of rodent (Murinae, Muridae, Rodentia) from the lower karst region of Northeastern Vietnam. Am Mus Novit 2006, 3571:1-41.

16. Musser G, Carleton M: Superfamily Muroidea. In Mammal species of the world: A taxonomic and geographic reference Volume 2. 3rd edition. Edited by: Wilson DE, Reeder DM. Baltimore: Johns Hopkins University; 2005:894-1531.

17. Lecompte E, Aplin K, Denys C, Catzeflis F, Chades M, Chevret P: Phylogeny and biogeography of African Murinae based on mitochondrial and nuclear gene sequences with a new tribal classification of the subfamily. BMC Evol Bio/ 2008, 8:199.

18. Myers N, Mittermeier RA, Mittermeier CG, da Fonseca GA, Kent J: . Biodiversity hotspots for conservation priorities. Nature 2000, 403:853-858.

19. Matsui S: Protecting human and ecological health under viral threats in Asia. Water Sci Technol 2005, 51:91-97.

20. Forman S, Hungerford N, Yamakawa M, Yanase T, Tsai HJ, Joo YS, Yang DK, Nha JJ: Climate change impacts and risks for animal health in Asia. Climate change and pathogens Rev Sci Tech, Office International des Epizooties 27 2008:581-597.

21. Rowe KC, Reno ML, Richmond DM, Adkins RM, Steppan SJ: Pliocene colonization and adaptive radiations in Australia and New Guinea Sahul Multilocus systematics of the old endemic rodents Muroidea Murinae. Mol Phylogenet Evol 2008, 47:84-101.

22. Xiao S, LeDuC J, Chu Y, Schmaljohn C: Phylogenetic analyses of virus isolates in the genus Hantavirus, family Bunyaviridae. Virology 1994 198:205-217.

23. Hugot JP, Plyusnina A, Herbreteau V, Nemirov K, Laakkonen, Lundkvist A, Supputamongkol Y, Henttonen $\mathrm{H}$, Plyusnin A: Genetic analysis of Thailand hantavirus in Bandicota indica trapped in Thailand. Virol $J$ 2006, 3:72-81

24. Coleman RE, Monkanna T, Linthicum KJ, Strickman DA, Frances SP, Tanskul P, Kollars TM Jr, Inlao I, Watcharapichat P, Khlaimanee N, Phulsuksombati D, Sangjun N, Lerdthusnee K: Occurrence of Orientia tsutsugamushi in small mammals from Thailand. Am J Trop Med Hyg 2003, 69:519-524

25. Robins J, Hingston M, Matisoo-Smith E, Ross H: Identifying Rattus species using mitochondrial DNA. Mol Ecol Notes 2007, 7:717-729.

26. Badenhorst $D$, Herbreteau V, Chaval Y, Pagès M, Robinson TJ, Rerkamnuaychoke W, Morand S, Hugot JP, Dobigny G: New karyotypic data for Asian rodents (Rodentia, Muridae) with the first report of Bchromosomes in the genus Mus. J Zool 2009. doi:10.1111/j.14697998.2009.00588.x

27. Bradley R, Baker R: A test of the genetic species concepts: cytochrome- $b$ sequences and mammals. J Mammal 2001, 82:960-973.

28. Pons J, Barraclough TG, Gomez-Zurita J, Cardoso A, Duran DP, Hazell S, Kamoun S, Sumlin WD, Vogler AP: Sequence-based species delimitation for the DNA taxonomy of undescribed insects. Syst Biol 2006, 55:595-609.

29. Jousselin E, Desdevises Y, Coeur d'acier A: Fine-scale cospeciation between Brachycaudus and Buchnera aphidicola: bacterial genome helps define species and evolutionary relationships in aphids. Proc Biol Sci 2009, 276:187-196

30. Fontaneto D, Herniou E, Boschetti C, Caprioli M, Melone G, Ricci C, Barraclough TG: Independently evolving species in asexual bdelloid rotifers. PLoS Biol 2007, 5:e87.

31. Fontaneto D, Boschetti C, Ricci C: Cryptic diversification in ancient sexual: evidence from the bdelloid rotifer Philodina flaviceps. J Evol Biol 2008, 21:580-587.

32. Bickford D, Lohman D, Sodhi N, Ng P, MeierR : Cryptic species as a window on diversity and conservation. Trends Ecol Evol 2006, 22:148-155

33. Marshall JD: Rats and mice of Thailand. In Mammals of Thailand Edited by: Lekagul B, McNeely JA. Saha Karn Bhaet Bangkok, Thailand; 1977:395-490

34. Corbet $\mathrm{G}$, Hill J: The Mammals of the Indomalayan Region: A Systematic Review Oxford University Press, USA: 1992

35. Aplin KP, Brown PR, Jacob J, Krebs CJ, Singleton GR: Field methods for rodent studies in Asia and the Indo-Pacific Canberra: Australian Centre for International Agricultural Research; 2003

36. Tollenaere C, Brouat C, Duplantier JM, Rahalison L, Rahelinirina S, Pascal M, Moné H, Mouahid G, Leirs H, Cosson JF: Phylogeography of the invasive species Rattus rattus in the western Indian Ocean, with special emphasis on the colonization history of Madagascar. J Biogeogr 2010, 37:398-410

37. Verneau O, Catzeflis F, Furano AV: Determining and dating recent rodent speciation events by using L1, LINE-1 retrotransposons. Proc Natl Acad SciUSA 1998, 95:11284-11289.

38. Michaux J, Chevret P, Renaud S: Morphological diversity of Old World rats and mice (Rodentia, Muridae) mandible in relation with phylogeny and adaptation. J Zoolog Syst Evol Res 2007, 45:263-279.

39. Jansa SA, Weksler M: Phylogeny of muroid rodents: relationships within and among major lineages as determined by IRBP gene sequences. Mol Phylogenet Evol 2004, 31:256-276.

40. Jansa SA, Barker FK, Heaney LR: The pattern and timing of diversification of Philippine endemic rodents: evidence from mitochondrial and nuclear gene sequences. Syst Biol 2006, 55:73-88.

41. Galtier N, Gouy M, Gautier C: SEAVIEW and PHYLO_WIN: two graphic tools for sequence alignment and molecular phylogeny. Comput Appl Biosci 1996, 12:543-548.

42. Rice P, Longden I, Bleasby A: EMBOSS: The European Molecular Biology Open Software Suite. Trends Genet 2000, 16:276-277.

43. Philippe H, Delsuc F, Brinkmann H, Lartillot N: Phylogenomics. Annual Review of Ecology, Evolution, and Systematics 2005, 36:541-562.

44. Xia X, Xie Z: DAMBE: software package for data analysis in molecular biology and evolution. J Hered 2001, 92:371-373.

45. Swofford DL: PAUP*. Phylogenetic Analysis using Parsimony, ${ }^{*}$ and other methods Sunderland, Massachusetts Sinauer Associates; 1998. Version 4

46. Phillips M, Delsuc F, Penny D: Genome-scale phylogeny and the detection of systematic biases. Mol Biol Evol 2004, 21:1455-1458.

47. Nylander JAA: MrAIC.pl. Program distributed by the author. Evolutionary Biology Centre, Uppsala University; 2004

48. Guindon S, Gascuel O: A simple, fast, and accurate algorithm to estimate large phylogenies by maximum likelihood. Syst Bio/ 2003, 52:696-704.

49. Stamatakis A: RAxML-VI-HPC: maximum likelihood-based phylogenetic analyses with thousands of taxa and mixed models. Bioinformatics 2006, 22:2688-2690.

50. Stamatakis A, Hoover P, Rougemont J: A rapid bootstrap algorithm for the RAxML Web servers. Syst Bio/ 2008, 57:758-771

51. Ronquist $F$, Huelsenbeck JP: MrBayes 3: Bayesian phylogenetic inference under mixed models. Bioinformatics 2003, 19:1572-1574.

52. Rambaut A, Drummond A: Tracer v1.4. 2003 [http://beast.bio.ed.ac.uk/ Tracer].

53. Shimodaira $\mathrm{H}$, Hasegawa M: Multiple comparisons of log-likelihoods with applications to phylogenetic inference. Mol Biol Evol 1999, 16:1114-1116

54. Thorne $\mathrm{JL}$, Kishino $\mathrm{H}$ : Divergence time and evolutionary rate estimation with multilocus data. Syst Biol 2002, 51:689-702. 
55. Rutschmann F: Bayesian molecular dating using PAML/MULTIDIVTIME. A step-by-step manual. 2005 [http://statgen.ncsu.edu/thorne/ multidivtime.html]. Version 1.4

56. Télétchéa F, Bernillon J, Duffraisse M, Laudet V, Hänni C: Molecular identification of vertebrate species by oligonucleotide microarray in food and forensic samples. J Appl Ecol 2008, 45:967-975.

57. Pagès $M$, Desse-Berset $N$, Brosse L, Hänni C, Berrebi P: Historical presence of the sturgeon Acipenser sturio in the Rhône basin determined by the analysis of ancient DNA cytochrome $b$ sequences. Conserv Genet 2009, 10:217-224

58. Hughes S, Hayden TJ, Douady CJ, Tougard C, Germonpré M, Stuart A, Lbova L, Carden RF, Hänni C, Say L: Molecular phylogeny of the extinct giant deer, Megaloceros giganteus. Mol Phylogenet Evo 2006, 40:285-291

59. Gilbert MT, Bandelt HJ, Hofreiter M, Barnes I: Assessing ancient DNA studies. Trends Ecol Evol 2005, 20:541-544.

60. Rohland N, Hofreiter M: Ancient DNA extraction from bones and teeth. Nat Protoc 2007, 2:1756-1762.

61. Sarkar I, Planet P, DeSalle R: CAOS Software for use in character based DNA barcoding. Mol Ecol Resour 2008, 8:1256-1259.

62. Hofreiter M, Jaenicke V, Serre D, Haeseler Av A, Pääbo S: DNA sequences from multiple amplifications reveal artifacts induced by cytosine deamination in ancient DNA. Nucleic Acids Res 2001, 29:4793-4799.

63. Gilbert MT, Hansen AJ, Willerslev E, Rudbeck L, Barnes I, Lynnerup N, Cooper A: Characterization of genetic miscoding lesions caused by postmortem damage. Am J Hum Genet 2003, 72:48-61.

64. Verneau O, Catzeflis F, Furano AV: Determination of the evolutionary relationships in Rattus sensu lato (Rodentia: Muridae). using L1, LINE-1. amplification events. J Mol Evol 1997, 45:424-436.

65. Aplin KP, Chesser T, ten Have J: Evolutionary biology of the genus Rattus: a profile of an archetypal rodent pest. In Rats, mice and people: rodent biology and management Edited by: Singleton GR, Hinds LA, Krebs CJ, Spratt DM. Canberra: Australian Centre for International Agricultural Research; 2003:487-498.

66. Jing $M, Y u H T$, Wu SH, Wang W, Zheng X: Phylogenetic relationships in genus Niviventer, Rodentia: Muridae in China inferred from complete mitochondrial cytochrome $b$ gene. Mol Phylogenet Evol 2007, 44:521-529.

67. Francis CM: A field guide to the mammals of South-East Asia London: New Holland; 2008

68. Asher RJ, Hofreiter M: Tenrec phylogeny and the noninvasive extraction of nuclear DNA. Syst Biol 2006, 55:181-194.

69. Irwin DM, Kocher TD, Wilson AC: Evolution of the cytochrome $b$ gene of mammals. J Mol Evol 1991, 32:128-144.

70. Poux C, Douzery EJ: Primate phylogeny, evolutionary rate variations, and divergence times: a contribution from the nuclear gene IRBP. Am J Phys Anthropol 2004, 124:1-16.

71. Ellerman JR: The Families and Genera of Living Rodents London, The British Museum Natural History; 1941

72. Jentink F: On a new genus and species of Mus from Madagascar. Notes of the Leyden Museum 1879:107-109.

73. Catzeflis F: Animal tissue collections for molecular genetics and systematics. Trends Ecol Evol 1991, 6:168

74. Aplin KP, Frost A, Tuan NP, Lan LP, Hung NM: Identification of rodents of the genus Bandicota in Vietnam and Cambodia. In Rats, mice and people: rodent biology and management Edited by: Singleton GR, Hinds LA, Krebs C J, Spratt DM. Canberra: Australian Centre for International Agricultural Research; 2003:531-535.

75. Musser G, Newcomb C: Malaysian murids and the giant rat of Sumatra. Bull Am Mu Nat Hist 1983, 174:327-598.

76. Lunde D, Aplin K: Leopoldamys neilli. IUCN 2008 [http:// www.iucnredlist.org]. IUCN Red List of Threatened Species. Downloaded on 13 March 2009

77. Musser G: Results of the Archbold expeditions $N^{\circ} 105$. Notes on systematics of Indo-malayan murid rodents, and descriptions of new genera and species from Ceylon, Sulawesi, and Philippines. Bull Am Mus Nat Hist 1981, 168:225-334.

78. Gorog A, Sinaga M, Engstrom M: Vicariance or dispersal? Historical biogeography of three Sunda shelf murine rodents (Maxomys surifer Leopoldamys sabanus and Maxomys whiteheadi). Biol J Linn Soc Lond 2004, 81:91-109. doi: $10.1186 / 1471-2148-10-184$

Cite this article as: Pagès et al., Revisiting the taxonomy of the Rattini tribe: a phylogeny-based delimitation of species boundaries BMC Evolutionary Biology 2010, 10:184

\section{Submit your next manuscript to BioMed Central and take full advantage of:}

- Convenient online submission

- Thorough peer review

- No space constraints or color figure charges

- Immediate publication on acceptance

- Inclusion in PubMed, CAS, Scopus and Google Scholar

- Research which is freely available for redistribution

Submit your manuscript at www.biomedcentral.com/submit
C BioMed Central 